\title{
Return Asymmetry and the Cross Section of Stock Returns
}

\author{
Zhongxiang $\mathrm{Xu}^{*} \quad$ Thanaset Chevapatrakul ${ }^{\dagger} \quad$ Xiafei $\mathrm{Li}^{\ddagger}$
}

April 2019

\begin{abstract}
This paper develops a new measure of return asymmetry, following Patil et al. (2012). We demonstrate that the return asymmetry measure helps explain the cross section of stock returns. Consistent with results in Barberis and Huang (2008), our empirical findings show that stocks with high return asymmetry exhibit low expected returns. The negative relation between return asymmetry and the cross section of stock returns persists for up to the 12-month forecast horizon and remains robust after controlling for the effects of skewness.
\end{abstract}

JEL classification : C20; C51; C53; G12; G17

Keywords : Empirical asset pricing; return asymmetry; skewness

${ }^{*}$ Tsinghua University, PBC School of Finance, 43 Chengfu Road, Beijing 100083, P.R. China. Email: xuzhx@pbcsf.tsinghua.edu.cn

$\dagger$ Corresponding author at Nottingham University Business School, Jubilee Campus, University of Nottingham, Nottingham, United Kingdom, NG8 1BB. Email: Thanaset.Chevapatrakul@nottingham.ac.uk. Tel: +44 (0) 1158232490 .

${ }^{\ddagger}$ Nottingham University Business School, Jubilee Campus, University of Nottingham, Nottingham, United Kingdom, NG8 1BB. Email: Xiafei.Li@nottingham.ac.uk. Tel: +44 (0) 1158466436. 


\section{Introduction}

Research on asset pricing has demonstrated that investors have preference for assets with lottery-like features which have potential to produce very large future returns with small probabilities. These assets are perceived by investors to be low-priced assets with high idiosyncratic volatility and positive idiosyncratic skewness (Kumar, 2009). The discovery dated back several decades earlier when Arditti (1967) showed that under very general assumptions, investors prefer to hold assets with positive skewness. More recently, results in Barberis and Huang (2008), which are based on a notion that preferences follow the cumulative prospect theory of Tversky and Kahnemann (1992), confirm investors' preference for lottery-like securities. Their findings, which are driven purely by the low probability, extreme return states, indicate that stocks whose returns are positively skewed attract more attention from investors and therefore generate lower expected returns. Brunnermeier et al. (2007) also arrive at similar conclusions. They show that investors prefer assets with positive skewness because of their natural tendency to be overly optimistic about payouts from their investments. Based on a one-period model of asset holdings where investors possess preference for skewness and a dataset of 60,000 individual investor accounts, Mitton and Vorkink (2007) demonstrate that investors intentionally underdiversify in order to gain larger exposure to skewness.

Although theoretical models developed during the past decades mostly agree on the negative relation between skewness and security returns, empirical investigation has so far yielded mixed results. For instance, employing firm-level data, Boyer et al. (2010) find that the expected idiosyncratic skewness and stock returns are negatively correlated while Bali and Murray (2013) note that physical skewness, measured as the skewness of daily returns over the past one year, fails to predict future equity and skewness asset returns. Moreover, using intraday data to compute weekly realised skewness, Amaya et al. (2015) show that the third moment of return distribution is negatively correlated with the cross-section of stock returns. In their paper, they also show that Boyer et al. (2010)'s results crucially hinge on the estimation window used in the calculation of skewness.

Some researchers employ total skewness and idiosyncratic skewness in their work while others opt for alternative measures of return skewness. As discussed in Bali et al. (2011), since investors hold the market portfolio in which idiosyncratic skewness is diversified away, it is therefore not idiosyncratic skewness, argued Bali et al. (2011), but systematic skewness (also called coskewness) that are priced in the cross section of stock returns. Rubinstein (1973), Kraus and Litzenberger (1976), and Harvey and Siddique (2000) provide evidence of a negative relation between systematic skewness of expected stock returns and returns on the market portfolio. Stocks with positive systematic skewness are more desirable 
and therefore command lower expected returns. Using forward-looking implied skewness, estimated from option prices, Conrad et al. (2013) demonstrate that risk-neutral skewness is negatively related to stock returns whereas Rehman and Vilkov (2012) and Bali et al. (2014) both find positive relationship between ex ante skewness and future stock returns.

Motivated by numerous research on the skewness preference theory and the lack of conclusive empirical evidence on the impact of skewness on asset returns, this paper proposes an alternative measure, following Patil et al. (2012), to examine the relation between the asymmetry of the return distribution and the cross section of stock returns. As a measure of the degree of asymmetry of a probability distribution, skewness suffers from two serious drawbacks. Firstly, since skewness is calculated using the sample mean, it is highly sensitive to outliers whose problem is exacerbated by the compounding effect of the third power. Because the skewness measure is heavily influenced by the behaviour at the tail of the distribution, it comes as no surprise that there is a lack of decisive evidence on the relationship between skewness and asset returns.

The second drawback of skewness involves its reliability as a measure of asymmetry of a return distribution. A large body of literature on statistical methods document that, as a measure of asymmetry, the conventional measure of skewness performs poorly under certain conditions. Doksum (1975), for instance, shows that the classical measures of location could impose a measurement error due to asymmetry. ${ }^{1}$ Patil et al. (2012) argue that the measure of skewness does not calibrate asymmetry in the density curve nor capture the asymmetry of the entire distribution if the tail behaviour dominates. ${ }^{2}$ The return asymmetry measure, which we employ to explain the cross section of stock returns in this paper, overcomes the two deficiencies mentioned above. By its construction, the measure is calibrated to lie between -1 and +1 , therefore facilitates comparison. Moreover, it captures the asymmetry of a return distribution in its entirety and is immune to the presence of outliers.

The findings in this paper are in line with the asset pricing implication for securities with lottery-like characteristics and complement a growing body of literature on the relation between investors' preference for skewness and subsequent asset returns (see Harvey and Siddique (2000), Mitton and Vorkink (2007), Conrad et al. (2013), and Jiang et al. (2018b), among others). Importantly, we demonstrate that our return asymmetry measure and the conventional skewness measures contain different pricing

\footnotetext{
${ }^{1}$ For detailed discussion on this issue, see van Zwet (1964), Doksum (1975), Oja (1981), MacGillivray (1986), Critchley and Jones (2008), and Patil et al. (2012).

${ }^{2}$ Several researchers, including Kim and White (2004), Conrad et al. (2013), and Ghysels et al. (2016), for example, overcome this issue by employing a quantile measure of skewness, developed by Bowley (1901) and Hinkley (1975), thus removing the influence of outliers on the estimates of the third moment. Another approach which has recently gained much attention utilises high-frequency return data to capture the unbiased estimate of skewness (cf. Neuberger (2012) and Amaya et al. (2015)).
} 
information which separately helps explain the cross section of stock returns. Results from both univariate and bivariate portfolio analyses, which control for the effects of return skewness, indicate that the return asymmetry measure is negatively related to expected stock returns: portfolios containing stocks with negative return asymmetry outperform portfolios containing stocks with positive return asymmetry. Specifically, zero-cost portfolios, which are long stocks with the lowest asymmetry measures and short stocks with the highest asymmetry measures, produce return spreads that are both statistically and economically significant. Furthermore, the return predictability of our asymmetry measure persists for up to the one-year forecasting horizon. At the individual stock level, results from the Fama and MacBeth (1973) regressions confirm that our return asymmetry helps explain the cross section of stock returns, even after controlling for the effects of the book-to-market ratio, momentum, short-term return reversal, liquidity, idiosyncratic volatility, demand for lottery-like stocks, and the various skewness measures.

We organise the rest of the paper in the following manner. We explain the calculation of the return asymmetry measure in Section 2. Section 3 compares the performance of the return asymmetry measure and the conventional skewness measure using simulated data. Section 4 describes our data and the construction of the control variables. We explain the empirical analysis procedures and discuss our findings in Section 5. Finally, Section 6 concludes the paper.

\section{Measure of Asymmetry}

We calculate the return asymmetry measure for each stock in our sample following the techniques described in Patil et al. (2012). At the end of each month, the measure of return asymmetry for a stock, denoted Asym, is computed as follows:

$$
\text { Asym }= \begin{cases}-\operatorname{corr}(f(R), F(R)) & \text { if } 0<\operatorname{var}(f(R))<\infty \\ 0 & \text { if } \operatorname{var}(f(R))=0\end{cases}
$$

where $\operatorname{corr}(\cdot)$ is the correlation function, $f(\cdot)$ and $F(\cdot)$ are the probability density function and the cumulative probability density function, respectively. By construction, the value of Asym lies between -1 and 1. A return distribution is positively asymmetric when Asym $>0$, negatively asymmetric when Asym $<0$ and symmetric when Asym $=0$.

Since the probability density function $f(\cdot)$ and the cumulative probability density function $F(\cdot)$ for the return on a security are unknown, they need to be approximated. In this paper, we employ a non-parametric smoothing approach, proposed by Rosenblatt et al. (1956) and Parzen (1962), to calculate the estimates of $f(\cdot)$ and $F(\cdot)$, denoted by 
$\hat{f}(\cdot)$ and $\hat{F}(\cdot)$, as follows:

$$
\begin{gathered}
\hat{f}(r)=\frac{1}{n h} \sum_{\ell=1}^{n} K\left(\frac{R_{i, \ell}-r}{h}\right) \\
\hat{F}(r)=\int_{-\infty}^{r} \hat{f}(u) d u
\end{gathered}
$$

where $R_{i, \ell}$ denotes the return on stock $i$ on day $\ell, n$ denotes the number of trading days during the estimation window, $h$ is the bandwidth, and $K(\cdot)$ is a non-negative bounded kernel function.

Following Jiang et al. (2018a) and Jiang et al. (2018b), we employ the standard Gaussian kernel

$$
K(z)=\frac{1}{\sqrt{2 \pi}} e^{-z^{2} / 2}
$$

to fit the stock return distribution. ${ }^{3}$ As for the choice of bandwidth estimation, we adopt the plug-in estimator of the asymptotically optimal bandwidth approach following Altman and Léger (1995). ${ }^{4}$

Let the estimation window be $T$ months, $S(t)$ denote a set of trading days between the first day of month $t-(T-1)$ and the end of month $t$, and $n$ be the number of trading days within $S(t)$. Furthermore, let $U_{i, d}=\hat{f}\left(R_{i, d}\right), V_{i, d}=\hat{F}\left(R_{i, d}\right), \bar{U}=\sum_{d \in S(t)} U_{i, d} / n$, and $\bar{V}=\sum_{d \in S(t)} V_{i, d} / n$, where $\hat{f}\left(R_{i, d}\right)$ and $\hat{F}\left(R_{i, d}\right)$ are the estimated probability density and the cumulative probability density for stock $i$ on day $d$ within $S(t)$, computed following Eqs. (2) and (3), respectively. We calculate the asymmetry measure for stock $i$ at the end of month $t$ as follows:

$$
\begin{aligned}
\operatorname{Asym}_{i, t} & =-\frac{\sum_{d \in S(t)}\left(U_{i, d}-\bar{U}\right)\left(V_{i, d}-\bar{V}\right)}{\sqrt{\left[\sum_{d \in S(t)}\left(U_{i, d}-\bar{U}\right)^{2}\right]\left[\sum_{d \in S(t)}\left(V_{i, d}-\bar{V}\right)^{2}\right]}} \\
& =-\frac{\sum_{d \in S(t)} U_{i, d} V_{i, d}-n \bar{U} \bar{V}}{\sqrt{\left(\sum_{d \in S(t)} U_{i, d}^{2}-n \bar{U}^{2}\right)\left(\sum_{d \in S(t)} V_{i, d}^{2}-n \bar{V}^{2}\right)}}
\end{aligned}
$$

where $A s y m_{i, t}$ is computed using all the daily return observations realised during the first trading day of month $t-(T-1)$ and the last trading day of month $t$. In order to examine

\footnotetext{
${ }^{3}$ As pointed out in Jiang et al. (2018a), the choice of bandwidth estimation can significantly affect the accuracy of a nonparametric kernel density estimator much more so than the choice of the kernel function.

${ }^{4}$ Among a number of approaches, while cross validation and Mallows's $C_{p}$ are the most popular approaches employed in the computation of bandwidth, it has been shown that the traditional crossvalidation techniques perform poorly in many simulations and real data studies (Park and Marron, 1990). Chu et al. (2015) point out that modern plug-in approaches have been consistently proved to possess superior performance compared to the cross-validation technique - particularly for simulated data that is not uniform. Moreover, Altman and Léger (1995) show that leave-one-out cross-validation as a biased reduction technique mimics the prediction problem.
} 
if the return predictability of return asymmetry is sensitive to the choice of estimation window, we estimate Asym for each individual stock using daily return observations from the previous 12 months (i.e., $T=12$ ) and the previous 60 months (i.e., $T=60$ ).

\section{Asymmetry vs. Skewness}

Do the measure of skewness and the measure of asymmetry always carry the same information? Not necessarily. Patil et al. (2012) note that their asymmetry measure and skewness often contradict each other: a more skewed distribution occasionally exhibits less asymmetry, and vice versa.

To examine if skewness and the asymmetry measure of Patil et al. (2012) are equally capable of detecting asymmetry of a distribution, we adopt a simulation approach, explained in Jiang et al. (2018b). We first generate 1,000 samples of 500 data points which are randomly drawn from each of the following distributions: $N(120,240), \chi^{2}(10)$ and $\operatorname{Beta}(1,3.7)-\operatorname{Beta}(1.3,2.3)$. Clearly, $N(120,240)$ is a symmetrical probability distribution whereas $\chi^{2}(10)$ is not. As for Beta $(1,3.7)$ - Beta(1.3,2.3), it is difficult to say - without a proper statistical test - whether the distribution is symmetric or asymmetric. Figure 1 shows that the Beta $(1,3.7)$ - Beta $(1.3,2.3)$ distribution appears to be asymmetric with a slightly longer left tail.

The next step involves calculating Asym and skewness, denoted by Skew, for each of the 1,000 samples of 500 data points drawn from each of the respective distributions. This step gives us a total of 1,000 statistics for Skew and Asym for each of the three distributions. Finally, we calculate the sample means, standard errors and $t$-statistics for both Skew and Asym. We report the statistics in Table 1.

The simulation results clearly show that while we fail to reject the null hypothesis of symmetry for the $N(120,240)$ distribution, we can comfortably reject the null hypothesis of symmetry for the $\chi^{2}(10)$ distribution at the $1 \%$ significance level. This result is to be expected. As for the $\operatorname{Beta}(1,3.7)$ - Beta(1.3,2.3) distribution, however, the skewness measure fails to detect asymmetry in the distribution because the null hypothesis of symmetry is not rejected. The average value of Skew equals 0.0011 with a $t$-statistic of 0.40 , indicating that Skew is not distinguishable from zero. On the other hand, the mean value of Asym for Beta $(1,3.7)$ - Beta $(1.3,2.3)$ is found to be statistically significant, with a $t$-statistic of -29.93 , suggesting that the distribution is not symmetric. Overall, the results show that skewness does not always capture asymmetry of a distribution, especially when the distribution is close to being symmetric, while the asymmetry measure of Patil et al. (2012) works well and is capable of detecting even a small degree of asymmetry. 


\section{Data \& Control Variables}

Our dataset contains return observations for all stocks listed on the New York Stock Exchange (NYSE), the American Stock Exchange (AMEX), and the NASDAQ, which we downloaded from the Center for Research in Security Prices (CRSP) database. ${ }^{5}$ The accounting information is obtained from the CRSP/Compustat Merged Database. We downloaded the size, value, momentum, profitability, and investment factors along with the market return and the risk-free rate from Kenneth French's website. ${ }^{6}$ Our dataset spans a period of just over 50 years between January 1963 and December 2014, giving us a total of 612 monthly return observations.

In order to isolate the impact of return asymmetry on expected future stock returns from that of other variables, which have previously been found to predict stock returns, the following control variables are included in our analyses: size, book-to-market (Fama and French, 1992, 1993), momentum (Jegadeesh and Titman, 1993), short-term return reversal (Jegadeesh, 1990), liquidity (Amihud, 2002), idiosyncratic volatility (Ang et al., 2006), demand for lottery-type stocks (Bali et al., 2011, 2017b), total skewness (Bali et al., 2011), idiosyncratic skewness (Boyer et al., 2010), and coskewness (Harvey and Siddique, 1999).

To calculate the size of stock $i$ at the end of month $t$, denoted by $S i z e_{i, t}$, we take the natural logarithm of the firm's market value at the end of the month, denoted by $M V_{i, t}$. The book-to-market ratio for stock $i$ in year $k$, denoted by $B M_{i, k}$, is the book value of equity for the fiscal year ending in year $k-1$ divided by the market value of equity at the end of December in year $k-1 .^{7}$ As described in Jegadeesh and Titman (1993), the momentum for security $i$ in month $t$, denoted by $\mathrm{Mom}_{i, t}$, is calculated as follows:

$$
\operatorname{Mom}_{i, t}=100 \times\left[\prod_{\tau \in\{t-11: t-1\}}\left(R_{i, \tau}+1\right)-1\right]
$$

where $R_{i, \tau}$ represents the return on stock $i$ in month $\tau$. The short-term return reversal for stock $i$ in month $t$, denoted by $R e v_{i, t}$, is estimated following Jegadeesh (1990) and Lehmann (1990) as the return on the stock in month $t-1$. The illiquidity measure of Amihud (2002), denoted by $I l l i q_{i, t}$, is computed using the average value of the ratio of the

\footnotetext{
${ }^{5}$ We exclude stocks with prices lower than $\$ 5$ and greater than $\$ 1000$ from our sample. We also drop stocks with fewer than 100 daily return observations. Returns on delisted stocks are adjusted following Shumway (1997).

${ }^{6}$ http://mba.tuck.dartmouth.edu/pages/faculty/ken.french/data_library.html

'The book value of equity is the value of stockholders' equity plus the balance sheet's deferred taxes and investment tax credit less the book value of preferred stock.
} 
absolute daily stock return to its daily dollar trading volume in the one-month period:

$$
\text { Illiq }_{i, t}=\frac{1}{n} \sum_{d \in S(t)} \frac{\left|R_{i, d}\right|}{V O L D_{i, d}}
$$

where $I_{l l i} q_{i, t}$ is the measure of illiquidity for stock $i$ in month $t, S(t)$ is the set of trading days in month $t, n$ is the number of trading days in $S(t), R_{i, d}$ and $V O L D_{i, d}$ are the daily return and the dollar trading volume of stock $i$ on day $d$ in month $t$, respectively. ${ }^{8}$ The illiquidity measure is scaled by a factor of 1,000 .

Following Ang et al. (2006), we calculate monthly idiosyncratic volatility, denoted Idio $\operatorname{Vol}_{i, t}$, as the standard deviation of the daily residuals:

$$
\operatorname{Idio}_{\text {Vol }}=\sqrt{\frac{1}{n-1} \sum_{d \in S(t)} \varepsilon_{i, d}^{2}}
$$

where $S(t)$ and $n$ are defined as above; $\varepsilon_{i, d}$ is the regression residual calculated from the Fama and French (1993)'s three-factor model (FF3):

$$
R_{i, d}-R_{f, d}=\alpha_{i}+\beta_{i, m}\left(R_{m, d}-R_{f, d}\right)+\beta_{i, S M B} S M B_{d}+\beta_{i, H M L} H M L_{d}+\varepsilon_{i, d}
$$

where $R_{i, d}, R_{m, d}$ and $R_{f, d}$ are the daily return of stock $i$, the daily return on the CRSP value-weighted index, and the daily risk-free rate on day $d$, respectively; $S M B_{d}$ and $H M L_{d}$ are, respectively, the daily size and book-to-market factors of Fama and French (1993) on day $d .^{9}$

We control for demand for lottery-like stocks in our analysis following Bali et al. (2011) and Bali et al. (2017b). At the end of each month $t$, demand for lottery-like stock $i$, denoted by $M A X_{i, t}$, is calculated as the maximum daily return value for stock $i$, realised during month $t$.

With regard to the skewness measures, we adopt a rolling window of 60 months to calculate both total and idiosyncratic skewness. Following Bali et al. (2011), total skewness for security $i$ in month $t$, denoted $S k e w_{i, t}$, is computed at the end of the month using daily returns realised during the previous 60 months:

$$
\operatorname{Skew}_{i, t}=\frac{1}{n} \sum_{d \in S(t)}\left(\frac{R_{i, d}-\bar{R}_{i}}{\hat{\sigma}_{i}}\right)^{3}
$$

\footnotetext{
${ }^{8}$ The volume for stocks traded on Nasdaq is adjusted according to Gao and Ritter (2010). Specifically, the volume is divided by 2 prior to 1 st February 2001, by 1.8 between 1st February 2001 and 31st December 2001, and by 1.6 between 2002 and 2003 .

${ }^{9}$ We also experiment with the residuals obtained from the CAPM and the Carhart's four-factor model to compute the idiosyncratic volatility as well as extending the estimation window to one year. We find that the effect of the idiosyncratic volatility remains unchanged.
} 
where $S(t)$ and $n$ are the set of trading days and the number of trading days in the 60-month estimation period, respectively; $\bar{R}_{i}$ and $\hat{\sigma}_{i}$ are the sample mean and the sample standard deviation of $R_{i, d}{ }^{10}$

Idiosyncratic skewness is calculated following Boyer et al. (2010). At the end of each month, we fit the FF3 model as shown in Eq. (8) to daily stock return data observed during the previous 60-month period. The idiosyncratic skewness for security $i$ at the end of month $t$ is calculated as follows:

$$
\operatorname{IdioSkew}_{i, t}=\frac{1}{n-2} \times \frac{\sum_{d \in S(t)} \varepsilon_{i, d}^{3}}{\text { Idio Vol } \operatorname{Vi}_{i, t}^{3}}
$$

where Idio Vol $_{i, t}$ is calculated following Eq. (7). ${ }^{11}$

Finally, to calculate coskewness, we follow the approach discussed in Bali et al. (2017a). First, we run the following regression:

$$
R_{i, t}-R_{f, t}=\alpha_{i}+\beta_{i, m}\left(R_{m, t}-R_{f, t}\right)+\varepsilon_{i, t}
$$

where $R_{i, t}, R_{m, t}$, and $R_{f, t}$ are the monthly return of stock $i$, the monthly return on the CRSP value-weighted index, and the monthly risk-free rate at the end of month $t$, respectively. Then, for each stock in the sample, the coskewness measure for stock $i$ in month $t$, denoted CoSkew $i, t$, is estimated as follows:

$$
\operatorname{CoSkew~}_{i, t}=\frac{E\left[\varepsilon_{i, t}\left(R_{m, t}-R_{f, t}\right)^{2}\right]}{\sqrt{E\left[\varepsilon_{i, t}^{2}\right]} E\left[\left(R_{m, t}-R_{f, t}\right)^{2}\right]}
$$

where $\varepsilon_{i, t}$ is the regression residual calculated from Eq. (11) above. Note that we use the daily returns realised during the previous 12 months to compute the security's coskewness following Harvey and Siddique (2000).

\section{$5 \quad$ Results \& Discussions}

\subsection{Return Asymmetry \& Stock Characteristics}

We begin our analysis by first examining portfolio characteristics in relation to our return asymmetry measure. Panel A of Table 2 reports the means, standard deviations, maxima and minima for all the variables employed in our analysis. The mean value of the return

\footnotetext{
${ }^{10}$ The first daily observation used in the estimation of total skewness is the first trading day of month $t-59$; the last daily observation is the last trading day of month $t$.

${ }^{11}$ We adjust the number of trading days by one for volatility and two for skewness as in the equations. We have similar results when we use alternative adjustment to $S(t)$.
} 
asymmetry measure is 0.02 , indicating that stocks in our sample exhibit small positive return asymmetry on average. Consistent with the return asymmetry measure, the mean values of both total skewness and idiosyncratic skewness are also positive. The Spearman's rank and the Pearson product-moment correlation coefficients, calculated as the time-series means of the cross-sectional values of the variables, are shown in the lower triangular and the upper triangular parts in Panel B of Table 2, respectively. Both correlation coefficients indicate that the measure of return asymmetry is positively correlated with size, total skewness, and idiosyncratic skewness with the Spearman's rank correlation coefficients of $0.63,0.54$ and 0.48 and the Pearson product-moment correlation coefficients of $0.57,0.53$ and 0.51 , respectively. We can report that the sign of approximately $44 \%$ of the values of the asymmetry measure in our sample differs from the sign of the skewness measures. Among the observations whose signs are different, about $60 \%$ (40\%) of them are those with negative (positive) skewness and positive (negative) asymmetry. This suggests that just slightly more than half of our sample contains observations whose asymmetry and skewness possess the same sign.

The positive correlation between Asym and $M V$ and the negative correlation between Asym and $B M$ suggest that large stocks as well as growth stocks tend to have positive asymmetry. The correlation between Asym and illiquidity is found to be strong and negative, indicating that illiquid stocks are likely to have negative return asymmetry. Importantly, the statistics in Panel B reveal that although return asymmetry and the three skewness measures can all be used to describe the shape of a return distribution, their information content differs to some extent as the correlation coefficients between Asym and the skewness measures are around $50 \%$ for Skew and IdioSkew, and almost zero for CoSkew. It is also worth noting that, consistent with the findings documented in Bali et al. (2011), we observe very strong correlation of around 0.90 between $M A X$ and Idio Vol, confirming the findings by Kumar (2009) that lottery-type stocks tend to have high idiosyncratic volatility.

To investigate the characteristics of stocks with different levels of Asym, we sort stocks into five quintile portfolios based on the value of Asym calculated at the end of each month using the 60-month estimation window. Table 3 shows the average values of $M V$, BM, Mom, Rev, Illiq, Idio Vol, MAX, Skew, CoSkew and IdioSkew for each of the quintile portfolios. The reported average values are the time-series means for each cross-sectional value of the variables. Based on the statistics presented in Table 3, it is clear that the mean values of $B M$ and Illiq exhibit a decreasing pattern across the five quintile portfolios, suggesting that stocks with low return asymmetry tend to be value and illiquid stocks. Interestingly, the findings in Table 3 and the correlation coefficients reported in Panel B of Table 2 point to a positive relation between return asymmetry and size, contradicting 
the claims in Kumar (2009), Han and Kumar (2013) as well as Bali et al. (2017b), who suggest that lottery-like stocks, which tend to be stocks with positive skewness, are likely to be small stocks. The evidence further points to the different information content carried by return asymmetry and skewness. Finally, it is also worth noting that the statistics in Table 3 indicate the lack of association between the measure of return asymmetry and both the demand for lottery-like stocks as well as the skewness measures since no clear pattern of Skew, CoSkew, IdioSkew, and MAX across the five Asym-sorted quintile portfolios emerges.

\subsection{Persistence of Returns Asymmetry}

In this section, we investigate the degree of persistence of return asymmetry in the average month-to-month portfolio transition matrices. Values shown in Table 4 are the average probabilities that a stock in Asym-sorted quintile portfolio $p$ at time $t$ will be in quintile portfolio $q$ at time $t+1$. If Asym is randomly distributed, we would expect each value to be around $20 \%$ since the probability that a stock falls into one of the five quintile portfolios in each month should be approximately equal.

As can be seen from the reported probabilities in Panel A of Table 4, the return asymmetry measure, estimated using daily return observations during the past 60 months, is highly persistent. In particular, the probability values along the diagonal axis are all greater than $80 \%$, indicating that it is highly likely that a stock will remain in the same Asym-sorted quintile portfolio month after month. The transition probability of $92.97 \%$ (92.60\%) for the first (fifth) Asym-sorted portfolio implies that, on average, securities in the first (fifth) quantile portfolio will continue to stay in the same portfolio after 6 months with a probability of approximately $65 \%$ (63\%).

Panel B of Table 4 reports the transition probabilities for the return asymmetry measure estimated using information on daily stock returns during the past 12 months. Compared to the probabilities reported in Panel A, the values in Panel B indicate that return asymmetry, calculated using a shorter estimation window of 12 months, is somewhat less persistent. This finding is to be expected because the estimation of return asymmetry using the 12-month window employs fewer overlapping observations. Our results also suggest that the probabilities that a stock which belongs to the extreme Asym-sorted portfolios (i.e., the first and the fifth portfolios) will remain in the same portfolios after one month are approximately $80 \%$. With regard to stocks in the intermediate Asym-sorted portfolios, the probabilities that they will remain in the same portfolios after one month are slightly below 60\%. Taken together, the reported probabilities in Panels A and B in Table 4 point to the highly persistent nature of return asymmetry. 


\subsection{Asymmetry Portfolios \& Portfolio Returns: Univariate Port- folio Analysis}

\subsubsection{Asymmetry Quintile Portfolios}

We begin our analysis on the relation between return asymmetry and the cross section of stock returns by performing a univariate portfolio sort based on return asymmetry. Specifically, at the end of each month, we sort stocks in our sample into five quintile portfolios based on the values of Asym which are computed using two different estimation windows: the 60-month and the 12-month windows. To ensure that the portfolio performance is robust to the weighting scheme, we experiment with both equal-weighted and value-weighted portfolios. After portfolio formation, the quintile portfolios are held for a period of one month, at which point all holdings are liquidated at the closing prices on the last trading day of the month and the monthly average stock returns are calculated. The sample used in the estimation of Asym is then rolled forward by one month and the procedure is repeated.

The univariate portfolio analysis results for Asym-sorted quintile portfolios when Asym is computed using 60 months of historical data are presented in Panel A of Table 5. Rows labelled "Average return" show monthly average portfolio returns obtained from investments in each of the quintile Asym-sorted portfolios. In addition to reporting the monthly average returns calculated from daily returns, recorded during the one-month holding period after portfolio construction, we also report the portfolio's risk-adjusted returns, or alphas, computed from the following models: the capital asset pricing model (CAPM) (Sharpe, 1964; Lintner, 1965); the Fama-French three-factor model (FF3) (Fama and French, 1993); the Cahart four-factor model (FFC) (Carhart, 1997); and the FamaFrench five-factor model (FF5) (Fama and French, 2015). Portfolio alphas are presented along rows labelled "CAPM alpha", "FF3 alpha", "FFC alpha" and "FF5 alpha".

Based on the monthly average returns and alphas presented in Table 5, there is a clear and strong negative relation between return asymmetry and expected stock returns for equal-weighted portfolios. Quintile portfolio one generates a substantially higher monthly average return and alphas than the other quintile portfolios. The monthly average return of the difference portfolio, which is long low-Asym stocks and short high-Asym stocks, shown under column labelled 1-5 equals $1.72 \%$ per month with a corresponding Newey and West (1987) t-statistic of 7.93. The portfolio alphas for the difference portfolios, calculated from the CAPM, FF3, FFC and FF5 models, range between $1.48 \%$ and $1.77 \%$ per month and are all statistically significant at the $1 \%$ significance level. While our FF3 alpha for the difference portfolio of $1.56 \%$ is slightly higher than the FF3 alpha of $1.30 \%$ reported in Boyer et al. (2010) when portfolios are sorted based on idiosyncratic volatility, 
our FFC alpha calculated following Carhart (1997) is comparable to the FFC alpha of $1.40 \%$ reported in Bali et al. (2017b) when portfolios are sorted according to demand for lottery-like stocks.

The results suggest that an investment strategy, which is long low-Asym stocks and short high-Asym stocks, generates economically significant risk-adjusted returns, confirming the negative relation between return asymmetry and future stock returns. The negative relation between Asym and expected stock returns remains strong in the value-weighted portfolios according to the univariate portfolio analysis results shown in the lower part of Panel A in Table 5. The alphas for the value-weighted difference portfolios are smaller compared to the alphas obtained for the equal-weighted difference portfolios but they remain statistically significant at the $1 \%$ level. The finding is consistent with the results reported by Harvey and Siddique (2000) who observe that the skewness risk premia are larger for equal-weighted coskewness-sorted portfolios than for value-weighted portfolios.

When portfolios are constructed based on the asymmetry measure computed using daily return observations during the past 12 months, the univariate portfolio analysis results point to a strong negative relation between return asymmetry and future stock returns for equal-weighted portfolios but not for value-weighted portfolios. The monthly average portfolio returns and alphas presented in the upper part of Panel B of Table 5 show a monotonically decreasing pattern as we move from portfolios one to five. The difference portfolios also generate statistically and economically significant monthly average returns and alphas. With regard to the performance of value-weighted portfolios, the alphas for the difference portfolio are no longer statistically significant except for the FFC model where the risk-adjusted return equals $0.16 \%$ per month with a Newey and West (1987) $t$-statistic of 1.92 .

Based on the results for the univariate portfolio analyses presented in Table 5, all of the equal-weighted quintile portfolios appear to outperform the respective value-weighted quintile portfolios. This result is compatible with the finding that large firms tend to have large return asymmetry and lower expected returns while small firms are likely to have small return asymmetry but higher expected returns. The long-short investment strategy therefore delivers superior portfolio returns when securities are equally weighted.

\subsubsection{Asymmetry Decile Portfolios}

To examine whether the relation between return asymmetry and expected stock returns is affected by the number of portfolios in the univariate portfolio analysis, we sort stocks in our sample into ten decile portfolios. The results are reported in Table 6 . The portfolio performance when Asym is computed using historical daily return data during the past 60 months confirms the negative relation between return asymmetry and expected stock 
returns according to the results presented in Panel A of Table 6. The monthly average return and the alphas estimated from the CAPM, FF3, FFC and FF5 models are all statistically and economically significant. They decline monotonically from the first decile portfolios to the ninth decile portfolios only to increase slightly at the 10th decile portfolios. The difference portfolios produce statistically significant monthly average returns and alphas, confirming a negative relation between return asymmetry and the one-month ahead expected stock returns. As far as the performance of the value-weighted decile portfolios is concerned, the negative relation previously observed in the equal-weighted portfolios appears to weaken in the value-weighted portfolios since, according to the results reported in the lower part of Panel A of Table 6, we do not detect a monotonically decreasing pattern of the monthly average return and alphas across the ten decile portfolios. The difference portfolios, however, still produce the monthly average return and alphas which are statistically significant at the $1 \%$ significance level.

Panel B of Table 6 shows the monthly average returns and alphas of the equal-weighted Asym-sorted decile portfolios where Asym is calculated using the 12-month estimation window. The monotonically decreasing pattern of the monthly average returns and alphas, previously observed in the quintile portfolios, remains virtually unchanged except in decile portfolio ten where the monthly average returns and alphas are slightly higher than the corresponding values at decile portfolio nine. This, however, does not affect the performance of the difference portfolios as the returns and alphas are highly statistically significant. In regard to the results for the value-weighted portfolios, similar to the results obtained when stocks are sorted into five quintile portfolios, no clear pattern emerges. The monthly average returns and alphas for the difference portfolios are not statistically significant either.

\subsubsection{Predicting $k$-Month-Ahead Returns}

The univariate portfolio analyses conducted thus far focus exclusively on the ability of return asymmetry to predict the one-month-ahead stock returns. Empirical evidence suggests that returns realised further into the future may be predictable. For example, Bali et al. (2016) show that the cross section of stock returns can be forecasted by Mom for up to 11 months ahead. In this section, we test if our return asymmetry measure can predict future monthly stock returns beyond the one-month period. Specifically, we examine the predictability of Asym at the 3-, 6- and 12-month horizons. Our procedure is as follows. At the end of month $t$, we calculate Asym for each stock in our sample using daily returns realised during the previous 60 months. Then, at the beginning of month $t+k$ where $k=3,6,12$, we sort stocks into five quintile portfolios based on the values of Asym. Each portfolio is held for a period of one month after which all the holdings in the 
portfolio are liquidated and the monthly average return and alphas are computed.

According to the portfolio performance reported in Table 7, the return asymmetry measure is a powerful predictor of monthly average stock returns for up to 3, 6, and even 12 months ahead. The results for the equal-weighted portfolios presented in Panel A indicate that the negative relation between Asym and future stock returns holds for all the forecast horizons under examination. We observe a monotonically declining pattern of the monthly average return and the CAPM alpha as we move from the first Asym-sorted portfolios to the fifth Asym-sorted portfolios for $k=3,6,12$. The FF3, FFC and FF5 alphas, however, decline monotonically from portfolio one to portfolio four only to increase slightly in portfolio five. The difference portfolios deliver economically significant monthly average returns and alphas, pointing to a strong relation between return asymmetry and future stock returns at the 3-, 6-, and 12-month horizons.

The results for the value-weighted portfolios reported in Panel B show a similar pattern to the results for the equal-weighted portfolios discussed earlier. The monotonically declining pattern of the monthly average return and the CAPM alpha across the five quintile portfolios previously observed remains intact. The pattern for the FF3, FFC and FF5 alphas is also similar to the pattern observed in the equal-weighted portfolios. It is worth noting that the monthly return and alphas for the difference value-weighted portfolios appear to be smaller compared to the monthly return and alphas for the difference equal-weighted portfolios. This is primarily due to the poor performance of the first value-weighted quintile portfolios, caused by underrepresentation of small stocks, which tend to produce higher returns in equal-weighted portfolios.

\subsubsection{Subperiod Analysis}

In order to verify that the negative relation between the return asymmetry measure and future stock returns holds in different sample periods, we divide our sample into two equal subperiods: 1963-1988 and 1989-2014. We then repeat the univariate portfolio analysis on each subperiod. For each subperiod, we form equal-weighted quintile portfolios based on the value of Asym, estimated at the end of each month. Similar to the analysis performed on the full sample, we experiment with the return asymmetry measure computed using both the 60 -month and the 12-month estimation windows to ensure that the results are robust to the choice of estimation window. After portfolio formation, portfolios are held for a period of one month, after which the monthly average return and associated alphas are computed. The procedure is repeated after the estimation window used in the calculation of Asym is rolled forward by one month.

We first show the average monthly returns and alphas for the five quintile portfolios formed based on the value of Asym estimated using the 60-month estimation window 
in Panel A of Table 8. The results show that return asymmetry and stock returns are negatively related in both subperiods; the monthly average returns and alphas fall monotonically from quintile portfolios one to four only to increase slightly in quintile portfolio five. The long-short zero-cost portfolios produce statistically significant monthly returns, suggesting that the cross-sectional stock return predictability of return asymmetry is robust to time periods of analysis.

Panel B of Table 8 shows the average monthly average return and the corresponding CAPM, FF3, FFC and FF5 alphas for the five quintile portfolios constructed based on the value of Asym estimated using the 12-month estimation window. It is clear that the negative relation between return asymmetry and future stock returns holds in both subperiods although the relation during the first half of the sample appears to be stronger than the relation during the second half. While the monthly average return and the alphas decline monotonically across the five quintile portfolios in the 1963-1988 period, the pattern is somewhat less prominent during 1989-2014. Nonetheless, the difference portfolios deliver economically significant monthly average returns and alphas in both periods.

\subsection{Asymmetry Portfolios \& Portfolio Returns: Bivariate Port- folio Analysis}

\subsubsection{Bivariate Dependent-Sort Portfolio Analysis based on $M V, B M, M o m$, Rev, Illiq, Idio Vol, and $M A X$}

In this section, we conduct bivariate portfolio analyses to examine the relation between the return asymmetry measure and expected stock returns, controlling separately for the effects of the following variables: $M V, B M$, Mom, Rev, Illiq, IdioVol, and MAX. Our procedure is as follows. As an example, we control for the size effect by first sorting stocks into five quintile equal-weighted portfolios based on the value of $M V$, observed at the end of the month prior to portfolio formation. Then within each $M V$-sorted quintile portfolio, we further sort stocks into five equal-weighted quintile portfolios based on the value of Asym, calculated using daily return observations realised during the previous 60 months. In this way, across the five $M V$-sorted quintile portfolios, Asym-sorted quintile portfolio one (five) contains securities with the lowest (highest) values of Asym but with different firm sizes.

For brevity, Table 9 reports the average one-month ahead FF3 alphas for each of the Asym-sorted quintile portfolios after controlling for $M V, B M$, Mom, Rev, Illiq, IdioVol, and $M A X$, separately. ${ }^{12}$ Similar to the univariate portfolio analysis results reported earlier,

\footnotetext{
${ }^{12}$ The monthly average returns and CAPM, FFC and FF5 alphas follow the same pattern as the FF3
} 
the monotonically decreasing pattern of the FF3 alpha remains intact after we control for $M V$, indicating significantly negative relation between return asymmetry and future stock returns. In line with the finding previously reported, the FF3 alpha of the difference portfolio of $0.25 \%$ per month is much smaller than the corresponding FF3 alpha of 1.56\% reported in Panel A of Table 5, suggesting that return asymmetry is somewhat correlated to firm size.

When we control for BM, Mom, Rev, Illiq, IdioVol, and MAX individually, we observe that the value of the FF3 alphas consistently decline as we move from quintile portfolio one to quintile portfolio four only to increase slightly in quintile portfolio five. The return differences between quintile portfolios one and five, after the effects of BM, Mom, Rev, Illiq, Idio Vol, and MAX are separately accounted for, are 1.21\%, 1.63\%, 1.58\%, 1.07\%, 1.61\%, and $1.04 \%$ per month, respectively. Notably, all the return differences are statistically significant at the $1 \%$ significance level. Overall, the FF3 alphas reported in Table 9 confirm the robust, negative relation between return asymmetry and future stock returns.

\subsubsection{Bivariate Independent-Sort Portfolio Analysis based on Skew, CoSkew and IdioSkew}

In this section, we explore whether return asymmetry and skewness possess similar information content. Using the independent-sort technique, we test whether our return asymmetry measure can be used to forecast one-month ahead stock returns after controlling for the effects of total skewness (Skew), coskewness (CoSkew), and idiosyncratic skewness (IdioSkew). Our approach is as follows. At the end of each month, we sort stocks into five equal-weighted quintile portfolios based on the value of Asym estimated using the same estimation window employed in the calculation of the skewness measure as described in Section $4 .{ }^{13}$ Then we further sort stocks within each equal-weighted Asym-sorted quintile portfolio into three equal-weighted portfolios based on the value of the skewness measure, using values at the 30 th and the 70 th percentiles as the cut-offs. ${ }^{14}$ The independent sort approach produces a total of 15 portfolios independently sorted by skewness and Asym. After portfolio formation, the portfolios are held for a period of one month after which the holdings are liquidated and the procedure is repeated. For each portfolio, we report

alpha. They are not reported in the paper and are available from the authors upon request.

${ }^{13}$ For consistency, the return asymmetry measure is estimated using the 60 -month window when we control for the effects of Skew and IdioSkew, and the 12-month window when we control for the effect of CoSkew.

${ }^{14}$ As an example, the first Skew-sorted portfolio contains stocks with Skew below the 30th percentile of Skew. The second Skew-sorted portfolio contains stocks with Skew between the 30th and the 70th percentiles of Skew. And finally, the third Skew-sorted portfolio contains stocks with Skew above the 70th percentile of Skew. 
the monthly FF3 alpha along with the Newey and West (1987) $t$-statistic. ${ }^{15}$

According to the statistics reported in Table 10, the estimated risk-adjusted returns consistently decline as we move from asymmetry quintile portfolios one to four. For some skewness portfolios, the alphas increase slightly as we move from asymmetry portfolios four to five. The return differences between the low Asym and the high Asym portfolios, controlling for Skew, CoSkew, and IdioSkew, range between 0.97\%-1.81\%, 1.39\%-1.73\%, and $1.03 \%-1.47 \%$ per month, respectively. More importantly, the return differences are all statistically significant at the $1 \%$ significance level. The bivariate independent-sort results suggest that the strong and negative relation between return asymmetry and the expected stock returns persist even when the effects of Skew, CoSkew, and IdioSkew are accounted for.

\subsection{Fama-MacBeth (1973) Cross-Sectional Regression}

We explore the effect of return asymmetry on expected returns at the individual-stock level by estimating the Fama and MacBeth (1973) regressions. At the end of each month, we run the following cross-sectional predictive regression model:

$$
R_{i, t+1}-R_{f, t+1}=\delta_{0, t}+\delta_{1, t} A_{s y m_{i, t}}+\boldsymbol{x}_{i, t}^{\prime} \boldsymbol{\theta}+\varepsilon_{i, t+1}
$$

where $R_{i, t+1}$ and $R_{f, t+1}$ denote the return of stock $i$ and the risk-free rate in month $t+1$, respectively; Asym $_{i, t}$ is the measure of return asymmetry for stock $i$ calculated at the end of month $t$ using the 60-month estimation window; and $\boldsymbol{x}_{i, t}$ is a vector whose elements are values of the other return predictors for stock $i$ observed in month $t$. We estimate seven model specifications in total.

The first specification regresses the monthly excess stock return of stock $i$ on the measure of return asymmetry. The second model includes both Size (i.e., $\ln M V$ ) and $\ln B M$ as additional predictors. The third model adds $M o m$ to the second model to account for the momentum effect. The fourth model adds the following variables to the third model: Rev, Illiq, Idio Vol, and MAX. We use the fourth model as a baseline model where we add Skew, CoSkew and IdioSkew separately to form the fifth, the sixth and the seventh models, respectively. Since observations in the first five years of the sample period are used in the estimation of the return asymmetry measure, the monthly cross-sectional regressions are conducted for the period between January 1968 and December 2014.

Table 11 reports the time-series averages of the cross-sectional regression coefficients over a period of 564 months, along with $t$-statistics calculated following Newey and West

\footnotetext{
${ }^{15}$ The results for the monthly average return, the CAPM, the FF4, and the FF5 alphas, and for portfolios, constructed using the bivariate dependent-sort technique, remain qualitatively unchanged. They are available from the authors upon request.
} 
(1987) with twelve lags. The results for the first model show a negative and statistically significant relation between return asymmetry and the one-month ahead expected stock returns at the individual stock level. The average slope parameter equals -1.93 with a $t$-statistic of -2.25 .

Adding the control variables in the regressions does not affect the negative relation between Asym and expected monthly stock returns in any way. The results for the second, the third and the fourth models suggest that after controlling for the effects of Size, BM, Mom, Rev, Illiq, Idio Vol, and MAX, the negative relation between the measure of return asymmetry and future stock returns remains strong. The coefficient on Asym varies between -1.41 and -1.78 and is statistically significant at the conventional significance levels. The parameters of the control variables are all statistically significant and correctly signed. ${ }^{16}$ Notably, that idiosyncratic volatility has a positive impact on the expected stock returns appears to contradict Ang et al. (2006). We offer two explanations based on Fu (2009) and Bali et al. (2011). Fu (2009) argues that idiosyncratic volatility are time-varying and suggests that the negative relation between idiosyncratic volatility and stock returns uncovered by Ang et al. (2006) is largely explained by the return reversal of a subset of small stocks with high idiosyncratic volatility. A somewhat similar explanation by Bali et al. (2011) is that idiosyncratic volatility is a proxy for $M A X$. Because lottery-like stocks tend to be small stocks with high $M A X$, when the effect of $M A X$ is accounted for, the positive relation between Idio $\mathrm{Vol}$ and the expected stock returns is therefore uncovered.

When we include each of the three skewness measures separately in the regressions, the coefficient on Asym remains negative and statistically significant, indicating that the crosssectional return predictability of Asym remains robust even after controlling for the effects of skewness. Importantly, the results from the Fama and MacBeth (1973) regressions show that the parameters on the skewness measures are all positive and statistically significant, contradicting existing evidence of negative relation between expected stock returns and skewness. Our results are compatible with Jiang et al. (2018b) who reveal that the effect of skewness on returns is positive during periods of low sentiment. Both our and their results appear to lend support to a notion that skewness, which by construction is heavily affected by the tail behaviour, may not be capable of consistently predicting expected stock returns.

\footnotetext{
${ }^{16}$ It is also worth noting that the parameters on $M A X$ and Idio Vol are both statistically significant a surprising result considering that the correlation between them is found to be quite high. This finding is also reported in Bali et al. (2011). Results from the bi-variate portfolio sorts suggest that idiosyncratic volatility does not completely explain the high (low) returns to low (high) $M A X$ stocks.
} 


\section{Conclusions}

In this paper, we investigate the asset pricing implication of return asymmetry. We propose a measure of asymmetry of a return distribution, following Patil et al. (2012), as an alternative to skewness. The measure quantify the degree of asymmetry in a return distribution by exploiting the relation between the probability density function and the cumulative probability density function of the stock return distribution. Using daily stock return observations between January 1963 and December 2014, we find that only about $60 \%$ of the values of the asymmetry measure have the same sign as the skewness measure. This finding suggests that the two measures contain different predictive information. Moreover, return asymmetry, estimated using the 60-month estimation window, appears to be highly persistent with more than $60 \%$ chance of a stock remaining in the same Asym-sorted quintile portfolio after 6 months.

Our portfolio-level analyses reveal a negative relation between the return asymmetry measure and expected stock returns. Our results from the univariate portfolio analyses show that the monthly average returns and alphas for portfolios containing stocks with low return asymmetry are higher than the monthly average returns and alphas for portfolios containing stocks with high return asymmetry. The long-short zero-cost portfolios are found to produce statistically and economically significant monthly returns. Further, the return asymmetry measure appears to possess explanatory power for up to the one-year forecasting horizon. Employing bivariate portfolio analyses, the negative relation between return asymmetry and expected stock returns remains strong even after we control for the size, book-to-market, momentum, short-term return reversal, liquidity, idiosyncratic volatility, demand for lottery-like stocks, total skewness, coskewness, and idiosyncratic skewness effects, separately.

At the stock level, the results from the Fama and MacBeth (1973) regressions indicate that return asymmetry predicts the one-month ahead cross section of stock returns. The cross-sectional predictability remains robust after controlling for variables that have previously been documented to forecast stock returns. Importantly, when we separately include total skewness, idiosyncratic skewness, coskewness in the Fama and MacBeth (1973) regressions along with our asymmetry measure, the coefficients on the skewness measures are found to be positive and highly statistically significant, contradicting previously documented empirical findings on the negative relation between skewness and the cross section of stock returns. The findings help explain the mixed evidence on the inability of skewness to consistently predict stock returns and support the use of alternative measures which better quantify asymmetry and more accurately describes the shape of the return distribution. 


\section{References}

Altman, N., Léger, C., 1995. Bandwidth selection for kernel distribution function estimation. Journal of Statistical Planning and Inference 46 (2), 195-214.

Amaya, D., Christoffersen, P., Jacobs, K., Vasquez, A., 2015. Does realized skewness predict the cross-section of equity returns? Journal of Financial Economics 118 (1), $135-167$.

Amihud, Y., 2002. Illiquidity and stock returns: cross-section and time-series effects. Journal of Financial Markets 5 (1), 31-56.

Ang, A., Hodrick, R. J., Xing, Y., Zhang, X., 2006. The cross-section of volatility and expected returns. Journal of Finance 61 (1), 259-299.

Arditti, F. D., 1967. Risk and the required return on equity. Journal of Finance, 19-36.

Bali, T. G., Brown, S., Tang, Y., 2017a. Is economic uncertainty priced in the cross-section of stock returns? Journal of Financial Economics 126 (3), 471-489.

Bali, T. G., Brown, S. J., Murray, S., Tang, Y., 2017b. A lottery-demand-based explanation of the beta anomaly. Journal of Financial and Quantitative Analysis 52 (6), 2369-2397.

Bali, T. G., Cakici, N., Whitelaw, R. F., 2011. Maxing out: Stocks as lotteries and the cross-section of expected returns. Journal of Financial Economics 99, 427-446.

Bali, T. G., Engle, R. F., Murray, S., 2016. Empirical asset pricing. John Wiley \& Sons.

Bali, T. G., Hu, J., Murray, S., 2014. Option implied volatility, skewness, and kurtosis and the cross-section of expected stock returns. Georgetown McDonough School of Business Research Paper.

Bali, T. G., Murray, S., 2013. Does risk-neutral skewness predict the cross-section of equity option portfolio returns? Journal of Financial and Quantitative Analysis 48 (04), $1145-1171$.

Barberis, N., Huang, M., 2008. Stocks as lotteries: The implications of probability weighting for security prices. American Economic Review.

Bowley, A. L., 1901. Elements of statistics. Staples Press Ltd., London. (6th ed., 1937).

Boyer, B., Mitton, T., Vorkink, K., 2010. Expected idiosyncratic skewness. Review of Financial Studies 23 (1), 169-202. 
Brunnermeier, M. K., Gollier, C., Parker, J. A., 2007. Optimal beliefs, asset prices, and the preference for skewed returns. American Economic Review 97 (2), 159-165.

Carhart, M. M., 1997. On persistence in mutual fund performance. Journal of Finance $52(1), 57-82$.

Chu, C.-Y., Henderson, D. J., Parmeter, C. F., 2015. Plug-in bandwidth selection for kernel density estimation with discrete data. Econometrics 3 (2), 199-214.

Conrad, J., Dittmar, R. F., Ghysels, E., 2013. Ex ante skewness and expected stock returns. Journal of Finance 68 (1), 85-124.

Critchley, F., Jones, M., 2008. Asymmetry and gradient asymmetry functions: Densitybased skewness and kurtosis. Scandinavian journal of statistics 35 (3), 415-437.

Doksum, K. A., 1975. Measures of location and asymmetry. Scandinavian Journal of Statistics, 11-22.

Fama, E. F., French, K. R., 1992. The cross-section of expected stock returns. Journal of Finance 47 (2), 427-465.

Fama, E. F., French, K. R., 1993. Common risk factors in the returns on stocks and bonds. Journal of Financial Economics 33 (1), 3-56.

Fama, E. F., French, K. R., 2015. A five-factor asset pricing model. Journal of Financial Economics 116 (1), 1-22.

Fama, E. F., MacBeth, J. D., 1973. Risk, return, and equilibrium: Empirical tests. The Journal of Political Economy, 607-636.

Fu, F., 2009. Idiosyncratic risk and the cross-section of expected stock returns. Journal of Financial Economics 91 (1), 24-37.

Gao, X., Ritter, J. R., 2010. The marketing of seasoned equity offerings. Journal of Financial Economics 97 (1), 33-52.

Ghysels, E., Plazzi, A., Valkanov, R., 2016. Why invest in emerging markets? the role of conditional return asymmetry. The Journal of Finance.

Han, B., Kumar, A., 2013. Speculative retail trading and asset prices. Journal of Financial and Quantitative Analysis 48 (2), 377-404.

Harvey, C. R., Siddique, A., 1999. Autoregressive conditional skewness. Journal of Financial and Quantitative Analysis 34 (04), 465-487. 
Harvey, C. R., Siddique, A., 2000. Conditional skewness in asset pricing tests. Journal of Finance, 1263-1295.

Hinkley, D. V., 1975. On power transformations to symmetry. Biometrika 62 (1), 101-111.

Jegadeesh, N., 1990. Evidence of predictable behavior of security returns. Journal of Finance, 881-898.

Jegadeesh, N., Titman, S., 1993. Returns to buying winners and selling losers: Implications for stock market efficiency. Journal of Finance 48 (1), 65-91.

Jiang, L., Wu, K., Zhou, G., 2018a. Aymmetry in stock comovments: an entropy approach. Journal of Financial and Quantitative Analysis 53 (4), 1479-1507.

Jiang, L., Wu, K., Zhou, G., Zhu, Y., 2018b. Stock return asymmetry: Beyond skewness. Tech. rep., Available at SSRN: https://ssrn.com/abstract=2660598.

Kim, T.-H., White, H., 2004. On more robust estimation of skewness and kurtosis. Finance Research Letters 1 (1), 56-73.

Kraus, A., Litzenberger, R. H., 1976. Skewness preference and the valuation of risk assets. Journal of Finance 31 (4), 1085-1100.

Kumar, A., 2009. Who gambles in the stock market? The Journal of Finance 64 (4), 1889-1933.

Lehmann, B. N., 1990. Fads, martingales, and market efficiency. Quarterly Journal of Economics 105, 1-28.

Lintner, J., 1965. The valuation of risk assets and the selection of risky investments in stock portfolios and capital budgets. The Review of Economics and Statistics, 13-37.

MacGillivray, H., 1986. Skewness and asymmetry: measures and orderings. The Annals of Statistics, 994-1011.

Mitton, T., Vorkink, K., 2007. Equilibrium underdiversification and the preference for skewness. Review of Financial Studies 20 (4), 1255-1288.

Neuberger, A., 2012. Realized skewness. Review of Financial Studies 25 (11), 3423-3455.

Newey, W. K., West, K. D., 1987. A simple, positive semi-definite, heteroskedasticity and autocorrelation consistent covariance matrix. Econometrica 55, 703-08.

Oja, H., 1981. On location, scale, skewness and kurtosis of univariate distributions. Scandinavian Journal of statistics, 154-168. 
Park, B. U., Marron, J. S., 1990. Comparison of data-driven bandwidth selectors. Journal of the American Statistical Association 85 (409), 66-72.

Parzen, E., 1962. On estimation of a probability density function and mode. The Annals of Mathematical Statistics, 1065-1076.

Patil, P., Patil, P., Bagkavos, D., 2012. A measure of asymmetry. Statistical Papers 53 (4), 971-985.

Rehman, Z., Vilkov, G., 2012. Risk-neutral skewness: Return predictability and its sources. Tech. rep., SSRN.

Rosenblatt, M., et al., 1956. Remarks on some nonparametric estimates of a density function. The Annals of Mathematical Statistics 27 (3), 832-837.

Rubinstein, M. E., 1973. The fundamental theorem of parameter-preference security valuation. Journal of Financial and Quantitative Analysis 8 (01), 61-69.

Sharpe, W. F., 1964. Capital asset prices: A theory of market equilibrium under conditions of risk*. Journal of Finance 19 (3), 425-442.

Shumway, T., 1997. The delisting bias in crsp data. Journal of Finance, 327-340.

Tversky, A., Kahnemann, D., 1992. Advances in prospect theory: Cumulative representation of uncertainty. Journal of Risk and Uncertainty 5, 297-323.

van Zwet, W. R., 1964. Convex transformations of random variables. Vol. 7. Mathematisch centrum. 


\section{Table 1}

\section{Tests of Asymmetry \& Skewness}

This table reports the means and $t$-statistics of skewness and the asymmetry measure of Patil et al. (2012) calculated on simulated samples drawn from the following distributions: $N(120,240)$, $\chi^{2}(10)$ and $\operatorname{Beta}(1,3.7)-\operatorname{Beta}(1.3,2.3) . t$-statistics are reported in parentheses. The symbols *, $* *$, and ${ }^{* * *}$ indicate statistical significance at the $10 \%, 5 \%$ and $1 \%$ significance level, respectively.

\begin{tabular}{lrrr}
\hline & $N(120,240)$ & $\chi^{2}(10)$ & $\begin{array}{r}\operatorname{Beta}(1,3.7)- \\
\operatorname{Beta}(1.3,2.3)\end{array}$ \\
\hline Skew & -0.0020 & $0.2334^{* * *}$ & 0.0011 \\
& $(-0.62)$ & $(65.78)$ & $(0.40)$ \\
Asym & -0.0013 & $0.1182^{* * *}$ & $-0.0657^{* * *}$ \\
& $(-0.64)$ & $(51.18)$ & $(-29.93)$ \\
\hline
\end{tabular}




\section{Table 2}

\section{Descriptive Statistics}

Panel A of this table reports the mean (Mean), the standard deviation (SD), the minimum (Min) and the maximum (Max) values of the variables employed in our analysis. The Spearman's rank and the Pearson product-moment correlation coefficients are shown in the lower triangular and the upper triangular parts of Panel B, respectively. The sample includes all the common stocks traded on the NYSE, AMEX, and Nasdaq between January 1963 to December 2014.

\begin{tabular}{|c|c|c|c|c|c|c|c|c|c|c|c|}
\hline & Asym & $M V$ & $B / M$ & Mom & Rev & Illiq & Idio Vol & $M A X$ & Skew & CoSkew & IdioSkew \\
\hline \multicolumn{12}{|c|}{ Panel A: Descriptive Statistics } \\
\hline Mean & 0.02 & 2377796 & 0.83 & 0.18 & 0.02 & 0.21 & 9.59 & 0.06 & 0.22 & -0.03 & 0.24 \\
\hline SD & 0.01 & 2188160 & 0.27 & 0.22 & 0.06 & 0.13 & 2.07 & 0.01 & 0.28 & 0.03 & 0.32 \\
\hline Min & -0.01 & 329656 & 0.44 & -0.37 & -0.27 & 0.10 & 6.13 & 0.03 & -0.52 & -0.14 & -0.55 \\
\hline Max & 0.05 & 9210423 & 2.10 & 1.03 & 0.25 & 0.52 & 19.25 & 0.15 & 0.77 & 0.05 & 0.86 \\
\hline \multicolumn{12}{|c|}{ Panel B: Correlation } \\
\hline Asym & & 0.57 & -0.54 & 0.20 & 0.05 & -0.45 & 0.13 & 0.21 & 0.53 & 0.04 & 0.51 \\
\hline$M V$ & 0.63 & & -0.39 & 0.15 & 0.05 & -0.55 & 0.03 & 0.19 & 0.76 & 0.21 & 0.75 \\
\hline$B / M$ & -0.53 & -0.48 & & 0.22 & 0.07 & 0.20 & -0.17 & -0.20 & -0.4 & 0.01 & -0.45 \\
\hline Mom & 0.23 & 0.21 & 0.18 & & -0.03 & -0.14 & -0.09 & -0.12 & 0.19 & -0.04 & 0.19 \\
\hline Rev & 0.08 & 0.09 & 0.07 & -0.05 & & -0.02 & 0.08 & 0.19 & 0.08 & 0.01 & 0.06 \\
\hline Illiq & -0.49 & -0.40 & 0.24 & -0.14 & -0.04 & & 0.27 & 0.04 & -0.24 & -0.19 & -0.09 \\
\hline Idio Vol & 0.02 & 0.05 & -0.18 & -0.10 & 0.14 & 0.41 & & 0.92 & 0.29 & -0.24 & 0.27 \\
\hline$M A X$ & 0.18 & 0.24 & -0.23 & -0.08 & 0.35 & 0.13 & 0.88 & & 0.34 & -0.14 & 0.31 \\
\hline Skew & 0.54 & 0.83 & -0.41 & 0.22 & 0.08 & -0.34 & 0.18 & 0.33 & & 0.23 & 0.91 \\
\hline CoSkew & 0.05 & 0.13 & 0.00 & -0.05 & 0.00 & -0.21 & -0.36 & -0.24 & 0.22 & & 0.18 \\
\hline IdioSkew & 0.48 & 0.85 & -0.38 & 0.21 & 0.07 & -0.19 & 0.17 & 0.30 & 0.89 & 0.16 & \\
\hline
\end{tabular}




\section{Table 3}

\section{Univariate Portfolio Analysis: Firm Characteristics \& Asymmetry Measure}

This table shows the average values of $M V, B M$, Mom, Rev, Illiq, Idio Vol, MAX, Skew, CoSkew and IdioSkew for Asym-sorted quintile portfolios. Quintile portfolio one contains stocks with the lowest $20 \%$ of Asym and quintile portfolio five contains stocks with the highest $20 \%$ Asym. The sample includes all common stocks traded on the NYSE, AMEX, and Nasdaq for the period between January 1963 and December 2014. The table presents the time-series means for each cross-sectional values. The return asymmetry measure is estimated using daily return observations realised during the previous 60 months.

\begin{tabular}{lrrrrr}
\hline \multirow{2}{*}{ Variable } & \multicolumn{5}{c}{ Quintile } \\
\cline { 2 - 6 } & 1 & 2 & 3 & 4 & 5 \\
\hline Asym & -0.09 & -0.01 & 0.02 & 0.04 & 0.10 \\
MV & 2180489 & 1701917 & 2037713 & 2535698 & 3431765 \\
BM & 1.08 & 0.91 & 0.80 & 0.71 & 0.67 \\
Mom & 0.15 & 0.15 & 0.17 & 0.20 & 0.22 \\
Rev & 0.01 & 0.01 & 0.01 & 0.02 & 0.02 \\
Illiq & 0.65 & 0.37 & 0.23 & 0.16 & 0.24 \\
IdioVol & 10.94 & 9.89 & 9.14 & 8.78 & 9.22 \\
MAX & 0.06 & 0.06 & 0.05 & 0.05 & 0.06 \\
Skew & 0.61 & 0.41 & 0.34 & 0.25 & 0.30 \\
CoSkew & -0.03 & -0.03 & -0.03 & -0.02 & -0.02 \\
IdioSkew & 0.60 & 0.42 & 0.36 & 0.29 & 0.34 \\
\hline
\end{tabular}




\section{Table 4}

\section{Transition Matrices for Asym-Sorted Portfolios}

At the end of each month $t$, all stocks are sorted into ascending Asym-sorted quintile portfolios. Panel A (B) shows the average probabilities that a stock in Asym-sorted quintile portfolio $p$ at time $t$ will be in quintile portfolio $q$ at time $t+1$ when Asym is calculated using the 60-month (12-month) estimation window.

\begin{tabular}{lllll}
\hline Asym $1_{t+1}$ & Asym $2_{t+1}$ & Asym $3_{t+1}$ & Asym $4_{t+1}$ & Asym $5_{t+1}$ \\
\hline
\end{tabular}

Panel A: 60-month estimation period

$\begin{array}{llllll}\text { Asym } 1_{t} & 92.97 \% & 5.53 \% & 0.47 \% & 0.34 \% & 0.69 \% \\ \text { Asym } 2_{t} & 5.58 \% & 85.62 \% & 8.09 \% & 0.43 \% & 0.27 \% \\ \text { Asym } 3_{t} & 0.43 \% & 8.21 \% & 82.46 \% & 8.65 \% & 0.26 \% \\ \text { Asym } 4_{t} & 0.31 \% & 0.42 \% & 8.78 \% & 84.42 \% & 6.08 \% \\ \text { Asym } 5_{t} & 0.65 \% & 0.26 \% & 0.27 \% & 6.22 \% & 92.60 \%\end{array}$

Panel B: 12-month estimation period

\begin{tabular}{llllll} 
Asym $1_{t}$ & $79.28 \%$ & $17.93 \%$ & $2.14 \%$ & $0.45 \%$ & $0.19 \%$ \\
Asym $2_{t}$ & $17.63 \%$ & $56.87 \%$ & $22.13 \%$ & $2.94 \%$ & $0.44 \%$ \\
Asym $3_{t}$ & $2.10 \%$ & $21.88 \%$ & $52.60 \%$ & $21.58 \%$ & $1.84 \%$ \\
Asym $4_{t}$ & $0.47 \%$ & $3.08 \%$ & $21.33 \%$ & $58.26 \%$ & $16.86 \%$ \\
Asym $5_{t}$ & $0.19 \%$ & $0.51 \%$ & $1.92 \%$ & $16.85 \%$ & $80.53 \%$ \\
\hline
\end{tabular}




\section{Table 5}

\section{Asymmetry Quintile Portfolios}

This table presents the results of univariate portfolio analyses of the relation between return asymmetry and future stock returns. At the end of each month, we calculate the return asymmetry measure, denoted Asym, using daily returns during the previous 12 and 60 months following Patil et al. (2012). Monthly portfolios are constructed by sorting all stocks in the sample into portfolios using quintile breakpoints calculated based on the values of Asym. Both equal-weighted and value-weighted portfolios are formed and held for a period of one month. Panel A (Panel B) shows the one-month ahead excess return and CAPM, FF3, FFC, and FF5 alphas for the portfolios formed based on Asym calculated using the 12-month (60-month) estimation window. The table also reports the average return and alphas of the portfolio that is long the first quintile portfolio and short the fifth quintile portfolio under column labelled $1-5$. $t$-statistics adjusted following Newey and West (1987) are reported in the parentheses. The symbols $*{ }^{* *}$, and $* * *$ indicate statistical significance at the $10 \%, 5 \%$ and $1 \%$ levels, respectively. Our sample includes all the common stocks traded on NYSE, AMEX, and Nasdaq between January 1963 and December 2014.

\begin{tabular}{lcccccc}
\hline \multirow{2}{*}{ Value } & \multicolumn{5}{c}{ Quintile portfolio } \\
\cline { 2 - 6 } & 1 & 2 & 3 & 4 & 5 & $1-5$ \\
\hline
\end{tabular}

Panel A: 60-month estimation period

\begin{tabular}{|c|c|c|c|c|c|c|}
\hline \multirow[b]{2}{*}{ Asym } & \multicolumn{5}{|c|}{ Equal-weighted portfolios } & \\
\hline & $\begin{array}{l}-0.09 \\
(-1.00)\end{array}$ & $\begin{array}{l}-0.01 \\
(-0.64)\end{array}$ & $\begin{array}{l}0.02 \\
(1.40)\end{array}$ & $\begin{array}{l}0.04 \\
(2.81)^{* * *}\end{array}$ & $\begin{array}{l}0.10 \\
(3.15)^{* * *}\end{array}$ & \\
\hline Average return & $\begin{array}{l}3.39 \\
(10.87)^{* * *}\end{array}$ & $\begin{array}{l}2.54 \\
(9.49) * * *\end{array}$ & $\begin{array}{l}1.95 \\
(8.31)^{* * *}\end{array}$ & $\begin{array}{l}1.67 \\
(7.43)^{* * *}\end{array}$ & $\begin{array}{l}1.67 \\
(6.81)^{* * *}\end{array}$ & $\begin{array}{l}1.72 \\
(7.93)^{* * *}\end{array}$ \\
\hline CAPM alpha & $\begin{array}{l}2.46 \\
(9.43)^{* * *}\end{array}$ & $\begin{array}{l}1.60 \\
(7.33)^{* * *}\end{array}$ & $\begin{array}{l}1.01 \\
(6.11)^{* * *}\end{array}$ & $\begin{array}{l}0.72 \\
(5.93)^{* * *}\end{array}$ & $\begin{array}{l}0.70 \\
(5.80)^{* * *}\end{array}$ & $\begin{array}{l}1.77 \\
(8.06)^{* * *}\end{array}$ \\
\hline FF3 alpha & $\begin{array}{l}2.22 \\
(11.49)^{* * *}\end{array}$ & $\begin{array}{l}1.36 \\
(9.44)^{* * *}\end{array}$ & $\begin{array}{l}0.82 \\
(8.39)^{* * *}\end{array}$ & $\begin{array}{l}0.59 \\
(7.81)^{* * *}\end{array}$ & $\begin{array}{l}0.66 \\
(7.98)^{* * *}\end{array}$ & $\begin{array}{l}1.56 \\
(8.18)^{* * *}\end{array}$ \\
\hline FFC alpha & $\begin{array}{l}2.25 \\
(11.20)^{* * *}\end{array}$ & $\begin{array}{l}1.43 \\
(9.43)^{* * *}\end{array}$ & $\begin{array}{l}0.89 \\
(9.22)^{* * *}\end{array}$ & $\begin{array}{l}0.65 \\
(8.49)^{* * *}\end{array}$ & $\begin{array}{l}0.74 \\
(7.93)^{* * *}\end{array}$ & $\begin{array}{l}1.51 \\
(7.99)^{* * *}\end{array}$ \\
\hline FF5 alpha & $\begin{array}{l}2.18 \\
(11.30)^{* * *}\end{array}$ & $\begin{array}{l}1.29 \\
(9.43)^{* * *}\end{array}$ & $\begin{array}{l}0.74 \\
(8.46)^{* * *}\end{array}$ & $\begin{array}{l}0.55 \\
(7.28)^{* * *}\end{array}$ & $\begin{array}{l}0.70 \\
(7.93)^{* * *}\end{array}$ & $\begin{array}{l}1.48 \\
(7.19)^{* * *}\end{array}$ \\
\hline \multicolumn{7}{|c|}{ Value-weighted portfolios } \\
\hline Asym & $\begin{array}{l}-0.07 \\
(-4.34)^{* * *}\end{array}$ & $\begin{array}{l}-0.01 \\
(-1.21)\end{array}$ & $\begin{array}{l}0.02 \\
(2.33)^{* *}\end{array}$ & $\begin{array}{l}0.04 \\
(4.18)^{* * *}\end{array}$ & $\begin{array}{l}0.09 \\
(10.91)^{* * *}\end{array}$ & \\
\hline Average return & $\begin{array}{l}1.77 \\
(7.35)^{* * *}\end{array}$ & $\begin{array}{l}1.29 \\
(6.66)^{* * *}\end{array}$ & $\begin{array}{l}1.09 \\
(6.10)^{* * *}\end{array}$ & $\begin{array}{l}0.96 \\
(5.19)^{* * *}\end{array}$ & $\begin{array}{l}0.94 \\
(4.53)^{* * *}\end{array}$ & $\begin{array}{l}0.83 \\
(4.92)^{* * *}\end{array}$ \\
\hline CAPM alpha & $\begin{array}{l}0.87 \\
(6.15) * * *\end{array}$ & $\begin{array}{l}0.41 \\
(4.71)^{* * *}\end{array}$ & $\begin{array}{l}0.21 \\
(2.93)^{* * *}\end{array}$ & $\begin{array}{l}0.10 \\
(2.41)^{* *}\end{array}$ & $\begin{array}{l}0.04 \\
(0.69)\end{array}$ & $\begin{array}{l}0.83 \\
(4.99)^{* * *}\end{array}$ \\
\hline FF3 alpha & $\begin{array}{l}0.71 \\
(5.93)^{* * *}\end{array}$ & $\begin{array}{l}0.30 \\
(3.75)^{* * *}\end{array}$ & $\begin{array}{l}0.14 \\
(2.03)^{* *}\end{array}$ & $\begin{array}{l}0.08 \\
(1.69)^{*}\end{array}$ & $\begin{array}{l}0.12 \\
(2.79) * * *\end{array}$ & $\begin{array}{l}0.58 \\
(4.31)^{* * *}\end{array}$ \\
\hline FFC alpha & $\begin{array}{l}0.79 \\
(6.24)^{* * *}\end{array}$ & $\begin{array}{l}0.38 \\
(4.32)^{* * *}\end{array}$ & $\begin{array}{l}0.21 \\
(3.08)^{* * *}\end{array}$ & $\begin{array}{l}0.08 \\
(1.84)^{*}\end{array}$ & $\begin{array}{l}0.11 \\
(2.26)^{* *}\end{array}$ & $\begin{array}{l}0.68 \\
(4.69)^{* * *}\end{array}$ \\
\hline FF5 alpha & $\begin{array}{l}0.69 \\
(5.29)^{* * *}\end{array}$ & $\begin{array}{l}0.25 \\
(3.25) * * *\end{array}$ & $\begin{array}{l}0.06 \\
(0.88)\end{array}$ & $\begin{array}{l}-0.03 \\
(-0.67)\end{array}$ & $\begin{array}{l}0.11 \\
(2.43)^{* *}\end{array}$ & $\begin{array}{l}0.57 \\
(3.91)^{* * *}\end{array}$ \\
\hline
\end{tabular}


Table 5: Continued

\begin{tabular}{|c|c|c|c|c|c|c|}
\hline \multirow{2}{*}{ Value } & \multicolumn{5}{|c|}{ Quintile portfolio } & \multirow[b]{2}{*}{$1-5$} \\
\hline & 1 & 2 & 3 & 4 & 5 & \\
\hline
\end{tabular}

Panel B: 12-month estimation period

\section{$\underline{\text { Equal-weighted portfolios }}$}

$\begin{array}{lllllll}\text { Asym } & -0.09 & -0.01 & 0.03 & 0.07 & 0.17 & \\ & (-4.89)^{* * *} & (-1.56) & (2.63)^{* * *} & (5.61)^{* * *} & (11.07)^{* * *} & \\ \text { Average return } & 3.03 & 2.75 & 2.35 & 2.04 & 1.84 & 1.20 \\ & (10.81)^{* * *} & (10.59)^{* * *} & (9.65)^{* * *} & (8.43)^{* * *} & (6.98)^{* * *} & (6.19)^{* * *} \\ \text { CAPM alpha } & 2.09 & 1.80 & 1.39 & 1.05 & 0.79 & 1.30 \\ & (11.04)^{* * *} & (9.42)^{* * *} & (8.48)^{* * *} & (7.15)^{* * *} & (4.87)^{* * *} & (6.63)^{* * *} \\ \text { FF3 alpha } & 1.82 & 1.55 & 1.17 & 0.89 & 0.74 & 1.08 \\ & (12.34)^{* * *} & (11.20)^{* * *} & (10.23)^{* * *} & (9.71)^{* * *} & (6.84)^{* * *} & (6.23)^{* * *} \\ \text { FFC alpha } & 1.99 & 1.69 & 1.25 & 0.94 & 0.76 & 1.23 \\ & (12.15)^{* * *} & (11.31)^{* * *} & (10.22)^{* * *} & (8.95)^{* * *} & (6.08)^{* * *} & (6.13)^{* * *} \\ \text { FF5 alpha } & 1.76 & 1.51 & 1.14 & 0.90 & 0.85 & 0.91 \\ & (11.88)^{* * *} & (11.27)^{* * *} & (10.43)^{* * *} & (9.79)^{* * *} & (7.64)^{* * *} & (5.18)^{* * *}\end{array}$

\section{Value-weighted portfolios}

$\begin{array}{lllllll}\text { Asym } & -0.08 & -0.01 & 0.03 & 0.07 & 0.17 \\ & (-14.29)^{* * *} & (-1.81)^{*} & (3.05)^{* * *} & (7.07)^{* * *} & (18.83)^{* * *} & \\ \text { Average return } & 1.10 & 1.09 & 1.08 & 1.04 & 0.97 & 0.13 \\ & (5.46)^{* * *} & (6.17)^{* * *} & (5.87)^{* * *} & (5.31)^{* * *} & (4.99)^{* * *} & (1.38) \\ \text { CAPM alpha } & 0.21 & 0.21 & 0.18 & 0.13 & 0.04 & 0.16 \\ & (2.75)^{* * *} & (3.03)^{* * *} & (4.00)^{* * *} & (3.82)^{* * *} & (0.76) & (1.92)^{*} \\ \text { FF3 alpha } & 0.20 & 0.19 & 0.19 & 0.13 & 0.12 & 0.08 \\ & (2.51)^{* *} & (3.09)^{* * *} & (4.16)^{* * *} & (3.54)^{* * *} & (2.34)^{* *} & (0.93) \\ \text { FFC alpha } & 0.24 & 0.28 & 0.23 & 0.14 & 0.10 & 0.14 \\ & (2.80)^{* * *} & (4.00)^{* * *} & (5.07)^{* * *} & (3.62)^{* * *} & (1.70)^{*} & (1.23) \\ \text { FF5 alpha } & 0.18 & 0.16 & 0.20 & 0.12 & 0.15 & 0.03 \\ & (2.09)^{* *} & (2.54)^{* *} & (4.69)^{* * *} & (2.98)^{* * *} & (2.76)^{* * *} & (0.25)\end{array}$




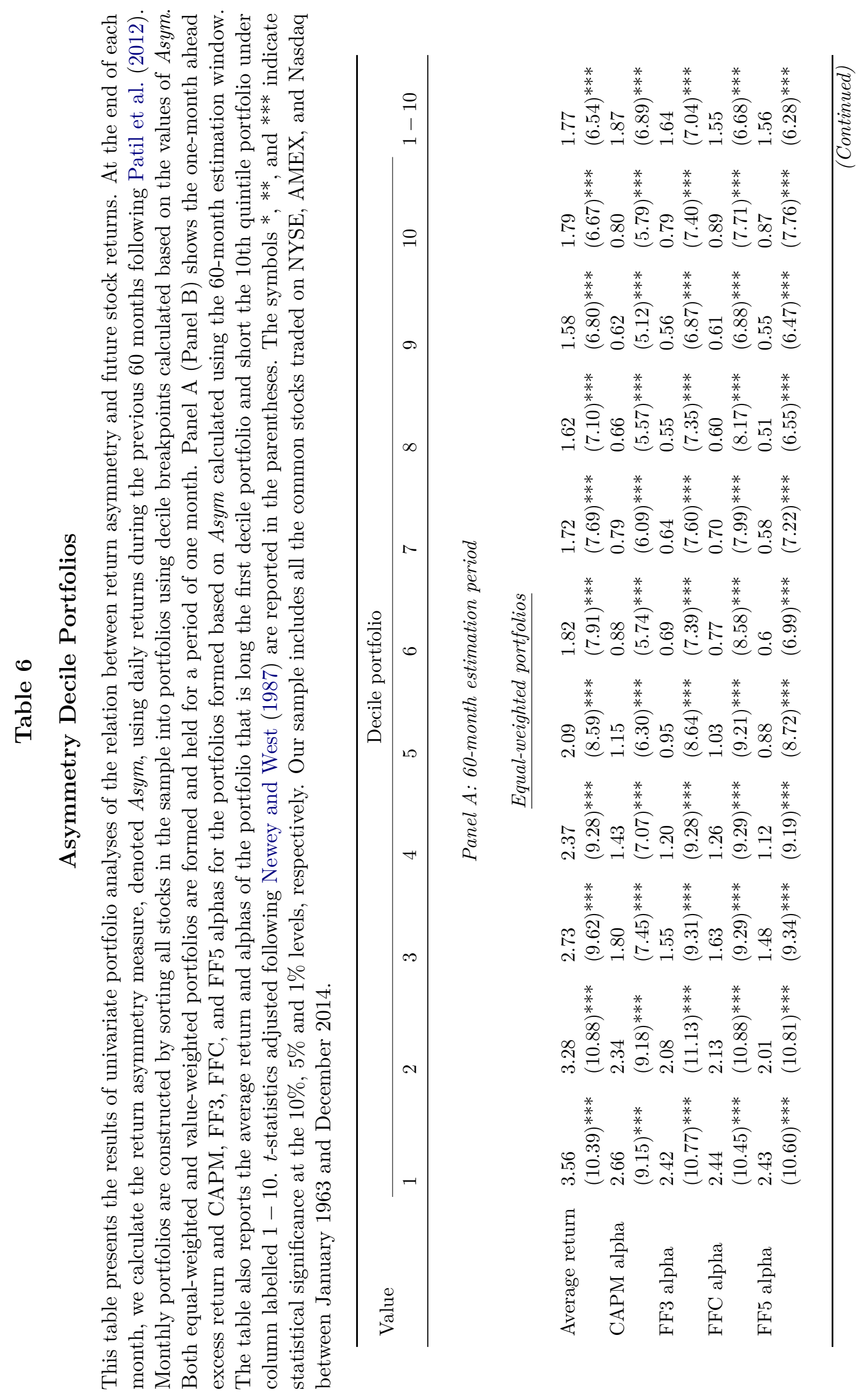




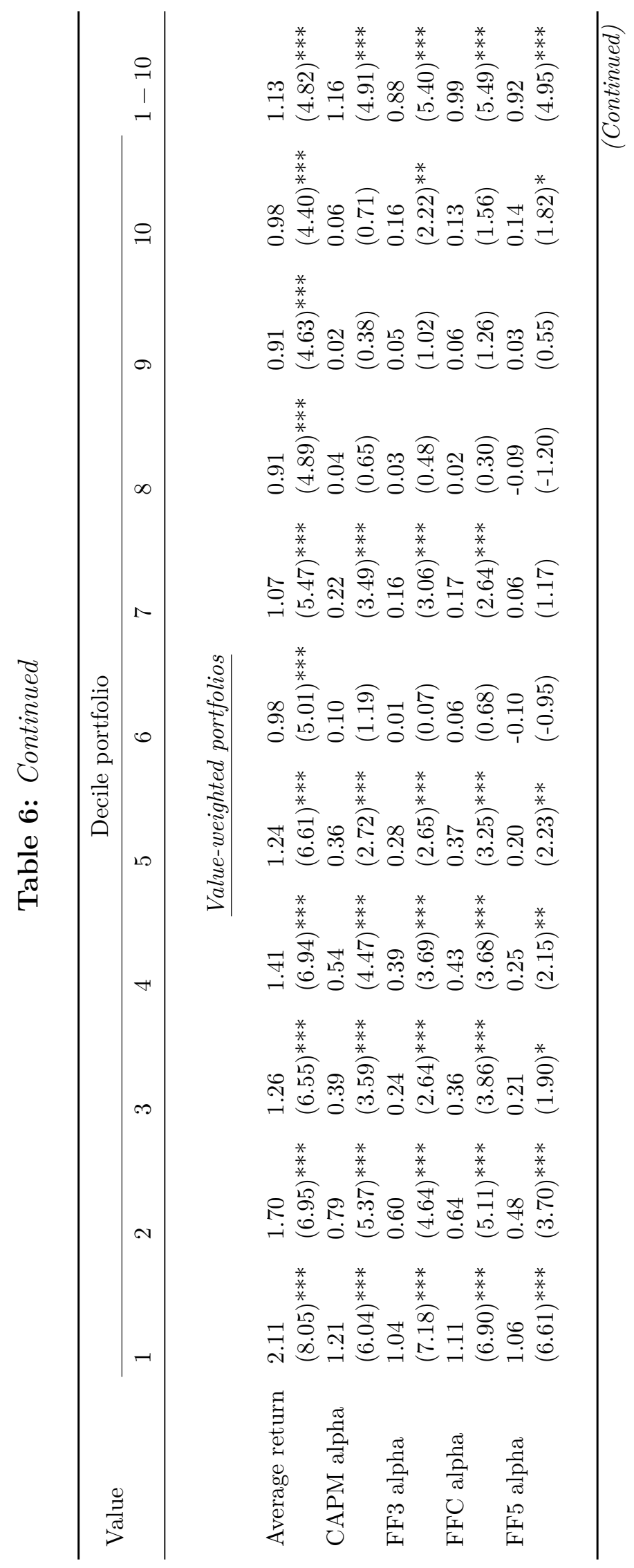




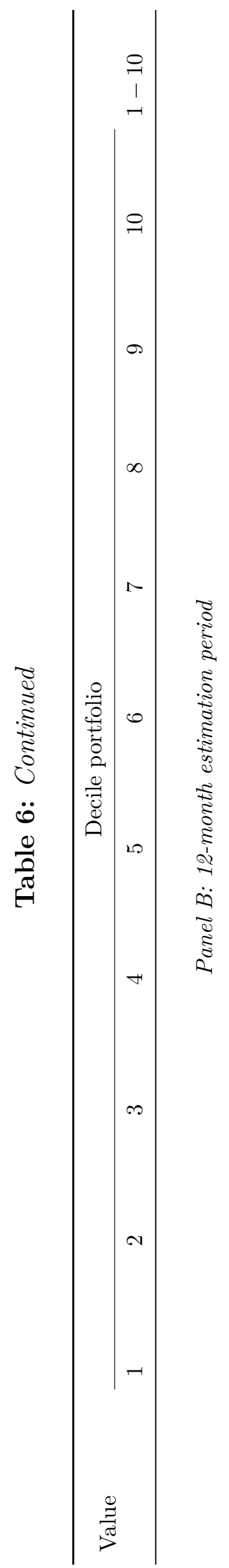

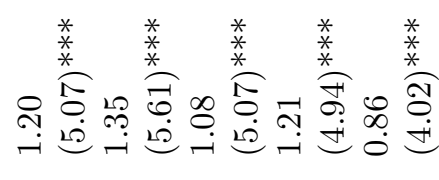

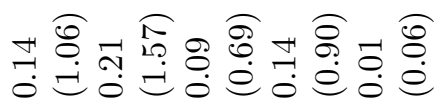

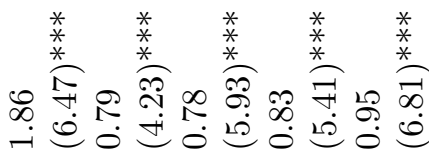

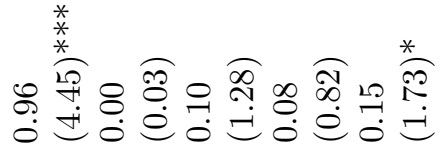

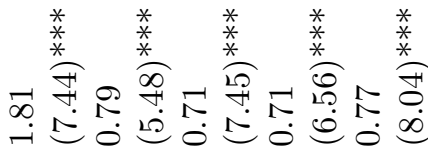

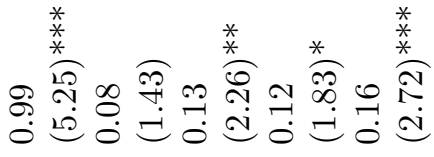

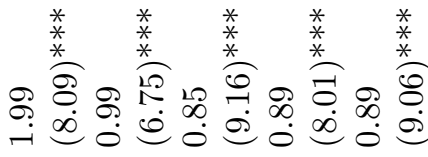

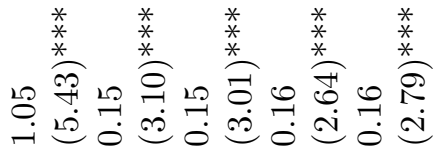

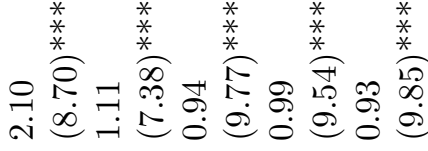

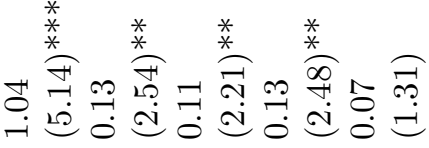

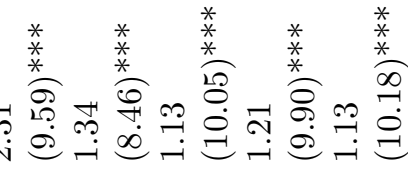

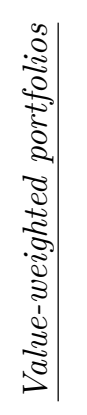

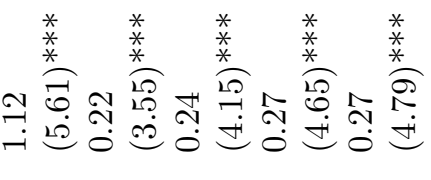

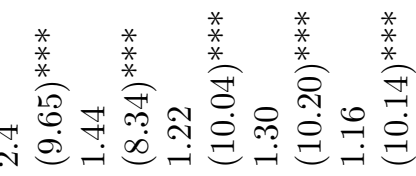

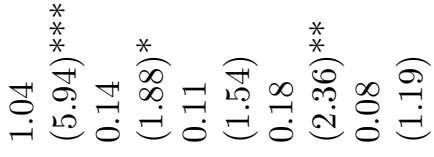

莘

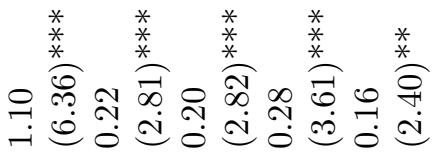

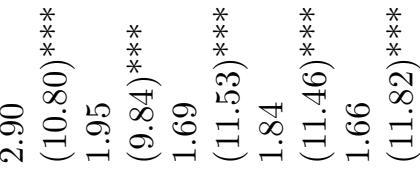

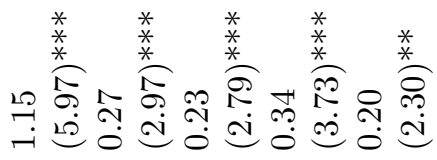

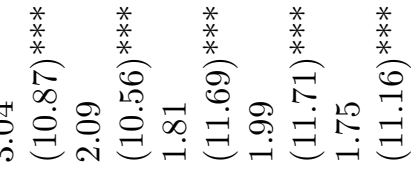

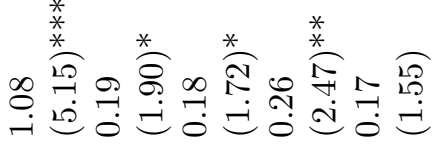

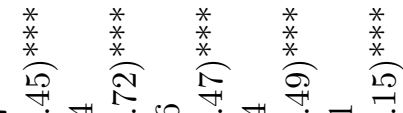

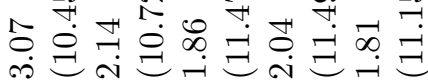

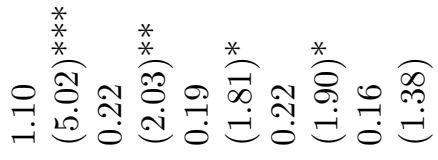

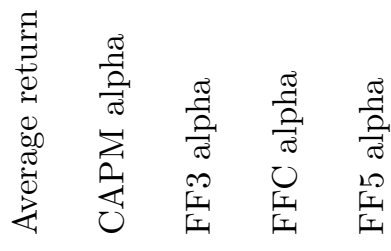

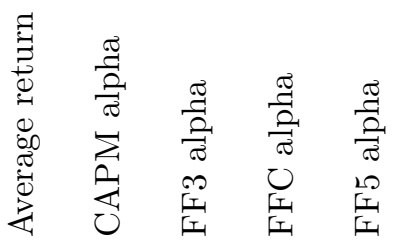




\section{Table 7}

\section{Asymmetry Quintile Portfolios: Predicting $k$-Month-Ahead Returns}

This table presents the results of univariate portfolio analyses of the relation between return asymmetry and future stock returns. At the end of each month, we calculate the return asymmetry measure, denoted Asym, using daily returns during the previous 60 months following Patil et al. (2012). Then $k-1$ months later, monthly portfolios are constructed by sorting all stocks in the sample into portfolios using quintile breakpoints calculated based on the values of Asym. Both equal-weighted and value-weighted portfolios are formed and held for a period of one month. We consider $k=3,6,12$, giving us forecasts of monthly returns 3-, 6- and 12-month ahead. Panel A (Panel B) shows the $k$-month ahead excess return and CAPM, FF3, FFC, and FF5 alphas for the equal-weighted (value-weighted) portfolios formed based on Asym calculated using the 60 -month estimation window where $k=3,6,12$. The table also reports the average return and alphas of the portfolio that is long the first quintile portfolio and short the fifth quintile portfolio under column labelled $1-5$. $t$-statistics adjusted following Newey and West (1987) are reported in the parentheses. The symbols $* * *$, and *** indicate statistical significance at the $10 \%, 5 \%$ and $1 \%$ levels, respectively. Our sample includes all the common stocks traded on NYSE, AMEX, and Nasdaq between January 1963 and December 2014.

\begin{tabular}{lllllll}
\hline \multirow{2}{*}{ Value } & \multicolumn{7}{c}{ Quintile portfolio } \\
\cline { 2 - 6 } & 1 & 2 & 3 & 4 & 5 & $1-5$ \\
\hline
\end{tabular}

Panel A: Equal-weighted portfolios

Three-month ahead forecasts $(k=3)$

$\begin{array}{lllllll}\text { Average return } & 3.34 & 2.50 & 1.96 & 1.71 & 1.71 & 1.63 \\ & (10.46)^{* * *} & (9.41)^{* * *} & (8.34)^{* * *} & (7.58)^{* * *} & (6.97)^{* * *} & (7.47)^{* * *} \\ \text { CAPM alpha } & 2.40 & 1.55 & 1.00 & 0.74 & 0.71 & 1.68 \\ & (8.96)^{* * *} & (7.25)^{* * *} & (6.21)^{* * *} & (5.94)^{* * *} & (5.87)^{* * *} & (7.61)^{* * *} \\ \text { FF3 alpha } & 2.17 & 1.33 & 0.82 & 0.60 & 0.67 & 1.50 \\ & (11.07)^{* * *} & (9.50)^{* * *} & (8.55)^{* * *} & (7.77)^{* * *} & (7.91)^{* * *} & (7.67)^{* * *} \\ \text { FFC alpha } & 2.18 & 1.38 & 0.90 & 0.67 & 0.77 & 1.41 \\ & (10.84)^{* * *} & (9.44)^{* * *} & (9.30)^{* * *} & (8.59)^{* * *} & (8.19)^{* * *} & (7.49)^{* * *} \\ \text { FF5 alpha } & 2.14 & 1.25 & 0.75 & 0.54 & 0.71 & 1.43 \\ & (10.81)^{* * *} & (9.52)^{* * *} & (8.59)^{* * *} & (7.08)^{* * *} & (7.56)^{* * *} & (6.63)^{* * *}\end{array}$

Six-month ahead forecasts $(k=6)$

$\begin{array}{lllllll}\text { Average return } & 3.26 & 2.48 & 1.93 & 1.67 & 1.67 & 1.59 \\ & (10.14)^{* * *} & (9.38)^{* * *} & (8.32)^{* * *} & (7.41)^{* * *} & (6.91)^{* * *} & (7.16)^{* * *} \\ \text { CAPM alpha } & 2.34 & 1.55 & 1.00 & 0.73 & 0.70 & 1.64 \\ & (8.57)^{* * *} & (7.34)^{* * *} & (6.31)^{* * *} & (5.69)^{* * *} & (5.85)^{* * *} & (7.26)^{* * *} \\ \text { FF3 alpha } & 2.15 & 1.34 & 0.82 & 0.59 & 0.65 & 1.50 \\ & (10.59)^{* * *} & (9.74)^{* * *} & (8.99)^{* * *} & (7.63)^{* * *} & (7.47)^{* * *} & (7.31)^{* * *} \\ \text { FFC alpha } & 2.13 & 1.38 & 0.89 & 0.66 & 0.78 & 1.35 \\ & (10.46)^{* * *} & (9.72)^{* * *} & (9.15)^{* * *} & (8.91)^{* * *} & (8.30)^{* * *} & (7.20)^{* * *} \\ \text { FF5 alpha } & 2.10 & 1.28 & 0.74 & 0.53 & 0.69 & 1.41 \\ & (10.48)^{* * *} & (9.82)^{* * *} & (9.22)^{* * *} & (6.87)^{* * *} & (6.89)^{* * *} & (6.28)^{* * *}\end{array}$

Twelve-month ahead forecasts $(k=12)$

\begin{tabular}{lllllll} 
Average return & 3.22 & 2.48 & 1.88 & 1.64 & 1.62 & 1.60 \\
& $(9.90)^{* * *}$ & $(9.33)^{* * *}$ & $(7.99)^{* * *}$ & $(7.22)^{* * *}$ & $(6.71)^{* * *}$ & $(6.95)^{* * *}$ \\
CAPM alpha & 2.30 & 1.57 & 0.96 & 0.72 & 0.67 & 1.63 \\
& $(8.53)^{* * *}$ & $(7.48)^{* * *}$ & $(5.95)^{* * *}$ & $(5.43)^{* * *}$ & $(5.56)^{* * *}$ & $(7.04)^{* * *}$ \\
FF3 alpha & 2.13 & 1.38 & 0.78 & 0.58 & 0.60 & 1.53 \\
& $(10.66)^{* * *}$ & $(10.29)^{* * *}$ & $(8.19)^{* * *}$ & $(7.43)^{* * *}$ & $(6.67)^{* * *}$ & $(7.10)^{* * *}$ \\
FFC alpha & 2.08 & 1.41 & 0.84 & 0.66 & 0.77 & 1.31 \\
& $(10.57)^{* * *}$ & $(9.97)^{* * *}$ & $(8.32)^{* * *}$ & $(8.79)^{* * *}$ & $(8.31)^{* * *}$ & $(6.95)^{* * *}$ \\
FF5 alpha & 2.10 & 1.33 & 0.71 & 0.50 & 0.63 & 1.47 \\
& $(10.39)^{* * *}$ & $(10.52)^{* * *}$ & $(8.62)^{* * *}$ & $(6.68)^{* * *}$ & $(5.74)^{* * *}$ & $(6.07)^{* * *}$ \\
& & & & & & \\
\hline
\end{tabular}


Table 7: Continued

\begin{tabular}{|c|c|c|c|c|c|c|}
\hline \multirow{2}{*}{ Value } & \multicolumn{5}{|c|}{ Quintile portfolio } & \multirow[b]{2}{*}{$1-5$} \\
\hline & 1 & 2 & 3 & 4 & 5 & \\
\hline \multicolumn{7}{|c|}{ Panel B: Value-weighted portfolios } \\
\hline \multicolumn{7}{|c|}{ Three-month ahead forecasts $(k=3)$} \\
\hline Average return & $\begin{array}{l}1.73 \\
(6.93)^{* * *}\end{array}$ & $\begin{array}{l}1.27 \\
(6.62)^{* * *}\end{array}$ & $\begin{array}{l}1.17 \\
(6.49)^{* * *}\end{array}$ & $\begin{array}{l}1.02 \\
(5.30)^{* * *}\end{array}$ & $\begin{array}{l}0.97 \\
(4.77)^{* * *}\end{array}$ & $\begin{array}{l}0.76 \\
(4.02)^{* * *}\end{array}$ \\
\hline CAPM alpha & $\begin{array}{l}0.79 \\
(4.59)^{* * *}\end{array}$ & $\begin{array}{l}0.38 \\
(4.55)^{* * *}\end{array}$ & $\begin{array}{l}0.28 \\
(4.43)^{* * *}\end{array}$ & $\begin{array}{l}0.13 \\
(2.93)^{* * *}\end{array}$ & $\begin{array}{l}0.05 \\
(0.87)\end{array}$ & $\begin{array}{l}0.74 \\
(3.75)^{* * *}\end{array}$ \\
\hline FF3 alpha & $\begin{array}{l}0.68 \\
(5.32)^{* * *}\end{array}$ & $\begin{array}{l}0.26 \\
(3.53) * * *\end{array}$ & $\begin{array}{l}0.21 \\
(3.57)^{* * *}\end{array}$ & $\begin{array}{l}0.10 \\
(2.12)^{* *}\end{array}$ & $\begin{array}{l}0.12 \\
(2.44)^{* *}\end{array}$ & $\begin{array}{l}0.56 \\
(3.77)^{* * *}\end{array}$ \\
\hline FFC alpha & $\begin{array}{l}0.81 \\
(5.83)^{* * *}\end{array}$ & $\begin{array}{l}0.33 \\
(4.29) * * *\end{array}$ & $\begin{array}{l}0.27 \\
(4.43)^{* * *}\end{array}$ & $\begin{array}{l}0.12 \\
(2.88)^{* * *}\end{array}$ & $\begin{array}{l}0.15 \\
(2.32)^{* *}\end{array}$ & $\begin{array}{l}0.66 \\
(4.45)^{* * *}\end{array}$ \\
\hline FF5 alpha & $\begin{array}{l}0.73 \\
(5.09)^{* * *}\end{array}$ & $\begin{array}{l}0.22 \\
(3.04) * * *\end{array}$ & $\begin{array}{l}0.13 \\
(2.21)^{* *}\end{array}$ & $\begin{array}{l}0.00 \\
(0.05)\end{array}$ & $\begin{array}{l}0.12 \\
(1.95)^{*}\end{array}$ & $\begin{array}{l}0.61 \\
(3.92)^{* * *}\end{array}$ \\
\hline \multicolumn{7}{|c|}{ Six-month ahead forecasts $(k=6)$} \\
\hline Average return & $\begin{array}{l}1.87 \\
(7.84)^{* * *}\end{array}$ & $\begin{array}{l}1.23 \\
(6.39)^{* * *}\end{array}$ & $\begin{array}{l}1.14 \\
(6.43)^{* * *}\end{array}$ & $\begin{array}{l}1.01 \\
(5.21)^{* * *}\end{array}$ & $\begin{array}{l}0.97 \\
(4.73)^{* * *}\end{array}$ & $\begin{array}{l}0.90 \\
(4.96)^{* * *}\end{array}$ \\
\hline CAPM alpha & $\begin{array}{l}0.95 \\
(5.65)^{* * *}\end{array}$ & $\begin{array}{l}0.36 \\
(3.27)^{* * *}\end{array}$ & $\begin{array}{l}0.27 \\
(3.69)^{* * *}\end{array}$ & $\begin{array}{l}0.14 \\
(2.98)^{* * *}\end{array}$ & $\begin{array}{l}0.06 \\
(1.19)\end{array}$ & $\begin{array}{l}0.89 \\
(4.81)^{* * *}\end{array}$ \\
\hline FF3 alpha & $\begin{array}{l}0.80 \\
(6.97)^{* * *}\end{array}$ & $\begin{array}{l}0.27 \\
(2.56)^{* *}\end{array}$ & $\begin{array}{l}0.20 \\
(3.02)^{* * *}\end{array}$ & $\begin{array}{l}0.11 \\
(2.14)^{* *}\end{array}$ & $\begin{array}{l}0.13 \\
(2.45)^{* *}\end{array}$ & $\begin{array}{l}0.67 \\
(5.90)^{* * *}\end{array}$ \\
\hline FFC alpha & $\begin{array}{l}0.86 \\
(6.66)^{* * *}\end{array}$ & $\begin{array}{l}0.38 \\
(3.96)^{* * *}\end{array}$ & $\begin{array}{l}0.25 \\
(3.92)^{* * *}\end{array}$ & $\begin{array}{l}0.15 \\
(2.98)^{* * *}\end{array}$ & $\begin{array}{l}0.21 \\
(3.45)^{* * *}\end{array}$ & $\begin{array}{l}0.65 \\
(5.19)^{* * *}\end{array}$ \\
\hline FF5 alpha & $\begin{array}{l}0.72 \\
(5.54)^{* * *}\end{array}$ & $\begin{array}{l}0.22 \\
(2.39)^{* *}\end{array}$ & $\begin{array}{l}0.12 \\
(2.04)^{* *}\end{array}$ & $\begin{array}{l}0.02 \\
(0.34)\end{array}$ & $\begin{array}{l}0.14 \\
(2.06)^{* *}\end{array}$ & $\begin{array}{l}0.58 \\
(4.21)^{* * *}\end{array}$ \\
\hline \multicolumn{7}{|c|}{ Twelve-month ahead forecasts $(k=12)$} \\
\hline Average return & $\begin{array}{l}1.70 \\
(7.11)^{* * *}\end{array}$ & $\begin{array}{l}1.46 \\
(7.91)^{* * *}\end{array}$ & $\begin{array}{l}1.05 \\
(5.23)^{* * *}\end{array}$ & $\begin{array}{l}1.03 \\
(5.43)^{* * *}\end{array}$ & $\begin{array}{l}0.93 \\
(4.39)^{* * *}\end{array}$ & $\begin{array}{l}0.77 \\
(4.35)^{* * *}\end{array}$ \\
\hline CAPM alpha & $\begin{array}{l}0.79 \\
(5.29)^{* * *}\end{array}$ & $\begin{array}{l}0.62 \\
(5.25)^{* * *}\end{array}$ & $\begin{array}{l}0.18 \\
(2.36)^{* *}\end{array}$ & $\begin{array}{l}0.17 \\
(2.51)^{* *}\end{array}$ & $\begin{array}{l}0.03 \\
(0.51)\end{array}$ & $\begin{array}{l}0.77 \\
(4.36)^{* * *}\end{array}$ \\
\hline FF3 alpha & $\begin{array}{l}0.65 \\
(5.64)^{* * *}\end{array}$ & $\begin{array}{l}0.49 \\
(5.12)^{* * *}\end{array}$ & $\begin{array}{l}0.14 \\
(1.76)^{*}\end{array}$ & $\begin{array}{l}0.12 \\
(1.96)^{*}\end{array}$ & $\begin{array}{l}0.06 \\
(1.05)\end{array}$ & $\begin{array}{l}0.60 \\
(4.39)^{* * *}\end{array}$ \\
\hline FFC alpha & $\begin{array}{l}0.72 \\
(5.88)^{* * *}\end{array}$ & $\begin{array}{l}0.55 \\
(5.02)^{* * *}\end{array}$ & $\begin{array}{l}0.22 \\
(3.18)^{* * *}\end{array}$ & $\begin{array}{l}0.20 \\
(3.67)^{* * *}\end{array}$ & $\begin{array}{l}0.22 \\
(3.85)^{* * *}\end{array}$ & $\begin{array}{l}0.49 \\
(3.57)^{* * *}\end{array}$ \\
\hline FF5 alpha & $\begin{array}{l}0.64 \\
(5.39)^{* * *}\end{array}$ & $\begin{array}{l}0.39 \\
(4.10) * * *\end{array}$ & $\begin{array}{l}0.09 \\
(1.37)\end{array}$ & $\begin{array}{l}0.02 \\
(0.36)\end{array}$ & $\begin{array}{l}0.08 \\
(1.02)\end{array}$ & $\begin{array}{l}0.56 \\
(3.71)^{* * *}\end{array}$ \\
\hline
\end{tabular}




\section{Table 8}

\section{Asymmetry Quintile Portfolios: Subperiod Analysis}

This table presents the results of univariate portfolio analyses of the relation between return asymmetry and future stock returns for two subperiods: 1963-1988 and 1989-2014. For each subperiod, we calculate the return asymmetry measure, denoted Asym, at the end of each month using daily returns during the previous 60 months following Patil et al. (2012). Monthly portfolios are constructed by sorting all stocks in the sample into portfolios using quintile breakpoints calculated based on the values of Asym. Both equal-weighted and value-weighted portfolios are formed and held for a period of one month. Panel A (Panel B) shows the one-month ahead excess return and CAPM, FF3, FFC, and FF5 alphas for the portfolios formed based on Asym calculated using the 12-month (60-month) estimation window. The table also reports the average return and alphas of the portfolio that is long the first quintile portfolio and short the fifth quintile portfolio under column labelled $1-5$. $t$-statistics adjusted following Newey and West (1987) are reported in the parentheses. The symbols *,**, and *** indicate statistical significance at the 10\%, $5 \%$ and $1 \%$ levels, respectively. Our sample includes all the common stocks traded on NYSE, AMEX, and Nasdaq between January 1963 and December 2014.

\begin{tabular}{lllllll}
\hline \multirow{2}{*}{ Value } & \multicolumn{5}{c}{ Quintile portfolio } \\
\cline { 2 - 5 } & 1 & 2 & 3 & 4 & 5 & $1-5$ \\
\hline
\end{tabular}

Panel A: 60-month estimation window

Subperiod 1963-1988

\begin{tabular}{lllllll} 
Average return & 3.19 & 2.13 & 1.63 & 1.45 & 1.37 & 1.82 \\
& $(6.79)^{* * *}$ & $(5.17)^{* * *}$ & $(4.19)^{* * *}$ & $(3.84)^{* * *}$ & $(3.36)^{* * *}$ & $(7.79)^{* * *}$ \\
CAPM alpha & 2.27 & 1.22 & 0.71 & 0.54 & 0.46 & 1.81 \\
& $(7.44)^{* * *}$ & $(4.91)^{* * *}$ & $(3.65)^{* * *}$ & $(4.18)^{* * *}$ & $(3.15)^{* * *}$ & $(7.75)^{* * *}$ \\
FF3 alpha & 1.85 & 0.84 & 0.45 & 0.38 & 0.42 & 1.44 \\
& $(8.66)^{* * *}$ & $(6.03)^{* * *}$ & $(4.23)^{* * *}$ & $(4.95)^{* * *}$ & $(4.23)^{* * *}$ & $(7.89)^{* * *}$ \\
FFC alpha & 1.85 & 0.89 & 0.53 & 0.40 & 0.42 & 1.42 \\
& $(8.48)^{* * *}$ & $(7.02)^{* * *}$ & $(5.00)^{* * *}$ & $(5.21)^{* * *}$ & $(4.19)^{* * *}$ & $(7.82)^{* * *}$ \\
FF5 alpha & 1.91 & 0.90 & 0.47 & 0.40 & 0.51 & 1.41 \\
& $(9.29)^{* * *}$ & $(7.60)^{* * *}$ & $(4.59)^{* * *}$ & $(5.17)^{* * *}$ & $(4.23)^{* * *}$ & $(9.14)^{* * *}$ \\
& & & & & & \\
& & \multicolumn{2}{r}{ Subperiod 1989-2014 } & & \\
Average return & 3.55 & 2.85 & 2.20 & 1.84 & 1.91 & 1.63 \\
& $(8.53)^{* * *}$ & $(8.47)^{* * *}$ & $(7.97)^{* * *}$ & $(6.93)^{* * *}$ & $(6.57)^{* * *}$ & $(4.76)^{* * *}$ \\
CAPM alpha & 2.67 & 1.95 & 1.29 & 0.90 & 0.90 & 1.78 \\
& $(6.71)^{* * *}$ & $(6.01)^{* * *}$ & $(5.44)^{* * *}$ & $(4.94)^{* * *}$ & $(5.25)^{* * *}$ & $(4.97)^{* * *}$ \\
FF3 alpha & 2.54 & 1.81 & 1.16 & 0.80 & 0.87 & 1.68 \\
& $(8.26)^{* * *}$ & $(8.87)^{* * *}$ & $(9.79)^{* * *}$ & $(7.84)^{* * *}$ & $(7.38)^{* * *}$ & $(5.14)^{* * *}$ \\
FFC alpha & 2.59 & 1.89 & 1.24 & 0.89 & 0.97 & 1.62 \\
& $(8.25)^{* * *}$ & $(8.76)^{* * *}$ & $(10.54)^{* * *}$ & $(9.08)^{* * *}$ & $(7.87)^{* * *}$ & $(5.19)^{* * *}$ \\
FF5 alpha & 2.51 & 1.69 & 1.03 & 0.72 & 0.90 & 1.62 \\
& $(8.00)^{* * *}$ & $(8.76)^{* * *}$ & $(11.13)^{* * *}$ & $(8.18)^{* * *}$ & $(7.82)^{* * *}$ & $(4.70)^{* * *}$ \\
\hline & & $r$ & & & & $($ Continued)
\end{tabular}


Table 8: Continued

\begin{tabular}{lllllll}
\hline \multirow{2}{*}{ Value } & \multicolumn{5}{c}{ Quintile portfolio } \\
\cline { 2 - 5 } & 1 & 2 & 3 & 4 & 5 & $1-5$ \\
\hline
\end{tabular}

Panel B: 12-month estimation window

Subperiod 1963-1988

$\begin{array}{lllllll}\text { Average return } & 3.18 & 2.51 & 2.02 & 1.74 & 1.50 & 1.69 \\ & (7.43)^{* * *} & (6.45)^{* * *} & (5.54)^{* * *} & (4.76)^{* * *} & (3.78)^{* * *} & (9.33)^{* * *} \\ \text { CAPM alpha } & 2.25 & 1.56 & 1.07 & 0.78 & 0.52 & 1.72 \\ & (9.93)^{* * *} & (7.04)^{* * *} & (5.50)^{* * *} & (4.33)^{* * *} & (2.67)^{* * *} & (9.45)^{* * *} \\ \text { FF3 alpha } & 1.82 & 1.13 & 0.70 & 0.52 & 0.36 & 1.46 \\ & (8.56)^{* * *} & (7.33)^{* * *} & (6.26)^{* * *} & (5.56)^{* * *} & (2.85)^{* * *} & (7.82)^{* * *} \\ \text { FFC alpha } & 2.08 & 1.34 & 0.78 & 0.48 & 0.23 & 1.85 \\ & (10.32)^{* * *} & (8.43)^{* * *} & (6.51)^{* * *} & (5.07)^{* * *} & (1.87)^{*} & (11.13)^{* * *} \\ \text { FF5 alpha } & 1.88 & 1.21 & 0.75 & 0.56 & 0.40 & 1.48 \\ & (8.56)^{* * *} & (8.17)^{* * *} & (7.31)^{* * *} & (6.14)^{* * *} & (2.94)^{* * *} & (6.77)^{* * *}\end{array}$

Subperiod 1989-2014

$\begin{array}{lllllll}\text { Average return } & 2.88 & 2.98 & 2.66 & 2.32 & 2.15 & 0.73 \\ & (7.91)^{* * *} & (8.74)^{* * *} & (8.55)^{* * *} & (7.48)^{* * *} & (6.37)^{* * *} & (2.34)^{* *} \\ \text { CAPM alpha } & 1.96 & 2.07 & 1.73 & 1.32 & 1.03 & 0.93 \\ & (6.56)^{* * *} & (7.05)^{* * *} & (7.31)^{* * *} & (6.25)^{* * *} & (4.22)^{* * *} & (2.75)^{* * *} \\ \text { FF3 alpha } & 1.82 & 1.96 & 1.64 & 1.25 & 1.06 & 0.76 \\ & (8.08)^{* * *} & (9.28)^{* * *} & (11.19)^{* * *} & (10.85)^{* * *} & (7.54)^{* * *} & (2.78)^{* * *} \\ \text { FFC alpha } & 1.96 & 2.07 & 1.72 & 1.34 & 1.15 & 0.81 \\ & (7.73)^{* * *} & (8.93)^{* * *} & (10.72)^{* * *} & (11.18)^{* * *} & (7.83)^{* * *} & (2.79)^{* * *} \\ \text { FF5 alpha } & 1.74 & 1.90 & 1.60 & 1.26 & 1.20 & 0.54 \\ & (7.68)^{* * *} & (9.03)^{* * *} & (11.09)^{* * *} & (10.90)^{* * *} & (8.31)^{* * *} & (1.93)^{*}\end{array}$




\section{Table 9}

Bivariate Portfolio Analysis: Controlling for $M V$, BM, Mom, Rev, Illiq, Idio Vol, and $M A X$

This table presents the results of bivariate portfolio analyses of the relation between return asymmetry and future stock returns after controlling for $M V$, BM, Mom, Rev, Illiq, Idio Vol, and $M A X$ separately. At the end of each month, we sort stocks into five quintile portfolios using breakpoints calculated based on the values of each of the control variables. Then within each quintile portfolio, we further sort stocks into five quintile portfolios based on the values of Asym computed using daily return data during the previous 60 months. The table reports the average FF3 alphas for each of the Asym-sorted quintile portfolios after controlling for each of the control variables. The table also reports the average return and alphas of the portfolio that is long the first Asym-sorted quintile portfolio and short the fifth Asym-sorted quintile portfolio under column labelled $1-5 . t$-statistics adjusted following Newey and West (1987) are reported in the parentheses. The symbols $*, * *$, and $* * *$ indicate statistical significance at the $10 \%, 5 \%$ and $1 \%$ levels, respectively. Our sample includes all the common stocks traded on NYSE, AMEX, and Nasdaq between January 1963 and December 2014.

\begin{tabular}{lllllll}
\hline \multirow{2}{*}{ Variable } & \multicolumn{5}{c}{ Quintile } \\
\cline { 2 - 6 } & 1 & 2 & 3 & 4 & 5 & $1-5$ \\
\hline MV & 2.06 & 2.04 & 1.96 & 1.92 & 1.81 & 0.25 \\
& $(10.93)^{* * *}$ & $(10.68)^{* * *}$ & $(10.32)^{* * *}$ & $(9.40)^{* * *}$ & $(9.56)^{* * *}$ & $(1.90)^{*}$ \\
BM & 2.07 & 1.26 & 0.91 & 0.78 & 0.86 & 1.21 \\
& $(11.05)^{* * *}$ & $(9.58)^{* * *}$ & $(9.14)^{* * *}$ & $(11.30)^{* * *}$ & $(9.62)^{* * *}$ & $(6.84)^{* * *}$ \\
Mom & 2.48 & 1.57 & 1.09 & 0.76 & 0.85 & 1.63 \\
& $(10.72)^{* * *}$ & $(9.90)^{* * *}$ & $(8.61)^{* * *}$ & $(8.05)^{* * *}$ & $(8.54)^{* * *}$ & $(7.21)^{* * *}$ \\
Rev & 2.45 & 1.53 & 1.06 & 0.81 & 0.87 & 1.58 \\
& $(10.95)^{* * *}$ & $(9.31)^{* * *}$ & $(9.51)^{* * *}$ & $(10.44)^{* * *}$ & $(9.69)^{* * *}$ & $(7.49)^{* * *}$ \\
Illiq & 2.07 & 1.39 & 1.07 & 0.91 & 1.00 & 1.07 \\
& $(12.63)^{* * *}$ & $(10.44)^{* * *}$ & $(10.24)^{* * *}$ & $(11.87)^{* * *}$ & $(10.08)^{* * *}$ & $(7.67)^{* * *}$ \\
Idio Vol & 2.88 & 2.06 & 1.53 & 1.20 & 1.27 & 1.61 \\
& $(9.20)^{* * *}$ & $(9.99)^{* * *}$ & $(8.01)^{* * *}$ & $(8.12)^{* * *}$ & $(9.01)^{* * *}$ & $(5.82)^{* * *}$ \\
MAX & 1.76 & 1.22 & 0.87 & 0.67 & 0.72 & 1.04 \\
& $(13.58)^{* * *}$ & $(10.45)^{* * *}$ & $(8.80)^{* * *}$ & $(8.08)^{* * *}$ & $(8.53)^{* * *}$ & $(8.23)^{* * *}$ \\
\hline
\end{tabular}




\section{Table 10}

\section{Bivariate Portfolio Analysis: Controlling for Skewness}

This table presents the results of bivariate portfolio analyses of the relation between return asymmetry and future stock returns after controlling for Skew, CoSkew and IdioSkew separately. At the end of each month, we independently sort stocks into five Asym-sorted quintile portfolios and three skewness-sorted portfolios. The breakpoints of each skewness are the 30th and 70th percentiles of the values of the skewness measure. Subscripts 1, 2 and 3 indicate portfolios containing stocks with the values of skewness below the 30th percentile, between the 30th and 70th percentiles and above the 70th percentile, respectively. The values of Asym at the end of each month are computed using daily returns observed during the previous 60 months. The table reports the average FF3 alphas for each of the Asym-sorted quintile portfolios along with the FF3 alpha of the portfolio that is long the first Asym-sorted quintile portfolio and short the fifth Asym-sorted quintile portfolio under column labelled $1-5 . t$-statistics adjusted following Newey and West (1987) are reported in the parentheses. The symbols *,**, and *** indicate statistical significance at the 10\%,5\% and 1\% levels, respectively. Our sample includes all the common stocks traded on NYSE, AMEX, and Nasdaq between January 1963 and December 2014.

\begin{tabular}{lllllll}
\hline \multirow{2}{*}{ Variable } & \multicolumn{5}{c}{ Quintile } \\
\cline { 2 - 5 } & 1 & 2 & 3 & 4 & 5 & $1-5$ \\
\hline Skew $_{1}$ & 1.59 & 0.95 & 0.58 & 0.53 & 0.61 & 0.97 \\
& $(10.60)^{* * *}$ & $(9.20)^{* * *}$ & $(6.58)^{* * *}$ & $(9.08)^{* * *}$ & $(8.06)^{* * *}$ & $(5.86)^{* * *}$ \\
Skew $_{2}$ & 2.48 & 1.34 & 0.80 & 0.68 & 0.67 & 1.81 \\
& $(10.28)^{* * *}$ & $(8.13)^{* * *}$ & $(8.47)^{* * *}$ & $(8.20)^{* * *}$ & $(6.61)^{* * *}$ & $(8.07)^{* * *}$ \\
Skew $_{3}$ & 2.96 & 2.01 & 1.55 & 1.24 & 1.56 & 1.41 \\
& $(11.64)^{* * *}$ & $(7.65)^{* * *}$ & $(8.11)^{* * *}$ & $(8.05)^{* * *}$ & $(9.32)^{* * *}$ & $(6.57)^{* * *}$ \\
& & & & & & \\
CoSkew $_{1}$ & 2.29 & 1.49 & 1.06 & 0.87 & 0.90 & 1.39 \\
& $(11.62)^{* * *}$ & $(10.28)^{* * *}$ & $(9.77)^{* * *}$ & $(8.54)^{* * *}$ & $(7.69)^{* * *}$ & $(7.00)^{* * *}$ \\
CoSkew $_{2}$ & 2.48 & 1.45 & 0.92 & 0.69 & 0.90 & 1.58 \\
& $(11.67)^{* * *}$ & $(8.95)^{* * *}$ & $(8.07)^{* * *}$ & $(9.41)^{* * *}$ & $(9.45)^{* * *}$ & $(7.59)^{* * *}$ \\
CoSkew $_{3}$ & 2.32 & 1.23 & 0.58 & 0.53 & 0.59 & 1.73 \\
& $(10.22)^{* * *}$ & $(7.17)^{* * *}$ & $(6.82)^{* * *}$ & $(8.42)^{* * *}$ & $(5.88)^{* * * *}$ & $(7.38)^{* * *}$ \\
& & & & & & \\
IdioSkew $_{1}$ & 1.63 & 1.01 & 0.61 & 0.57 & 0.60 & 1.03 \\
& $(11.12)^{* * *}$ & $(9.17)^{* * *}$ & $(6.90)^{* * *}$ & $(9.81)^{* * *}$ & $(8.03)^{* * * *}$ & $(6.28)^{* * *}$ \\
IdioSkew $_{2}$ & 2.56 & 1.38 & 0.82 & 0.68 & 0.67 & 1.89 \\
& $(10.46)^{* * *}$ & $(8.35)^{* * *}$ & $(8.80)^{* * *}$ & $(8.60)^{* * *}$ & $(7.16)^{* * * *}$ & $(8.04)^{* * *}$ \\
IdioSkew $_{3}$ & 2.85 & 1.87 & 1.41 & 1.07 & 1.38 & 1.47 \\
& $(10.86)^{* * *}$ & $(7.43)^{* * *}$ & $(8.38)^{* * *}$ & $(7.68)^{* * *}$ & $(8.36)^{* * * *}$ & $(6.65)^{* * *}$ \\
\hline
\end{tabular}




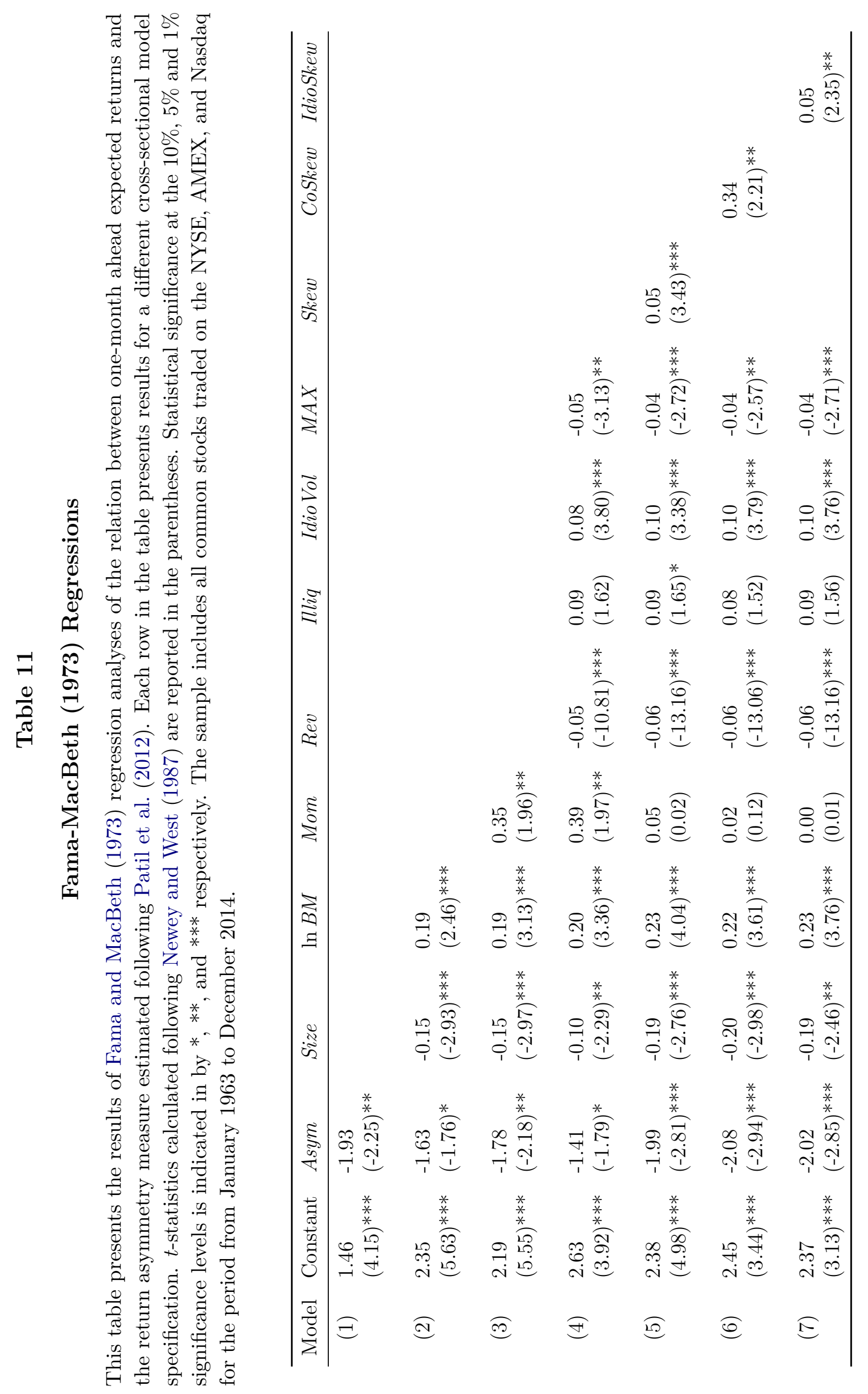


Figure 1: $\operatorname{Beta}(1,3.7)$ - $\operatorname{Beta}(1.3,2.3)$

We generate 1,000 samples of 500 data points which are randomly drawn from the Beta $(1,3.7)-$ $\operatorname{Beta}(1.3,2.3)$. The figure shows that the $\operatorname{Beta}(1,3.7)-\operatorname{Beta}(1.3,2.3)$ distribution appears to be asymmetric with a slightly longer left tail. We calculate skewness, denoted by Skew, and the asymmetry measure for each of the 1,000 samples of 500 data points. This gives us a total of 1,000 values of Skew and Asym for each of the three distributions. Finally, we calculate the sample means, standard errors and $t$-statistics for both Skew and Asym. The statistics are reported in Table 1.

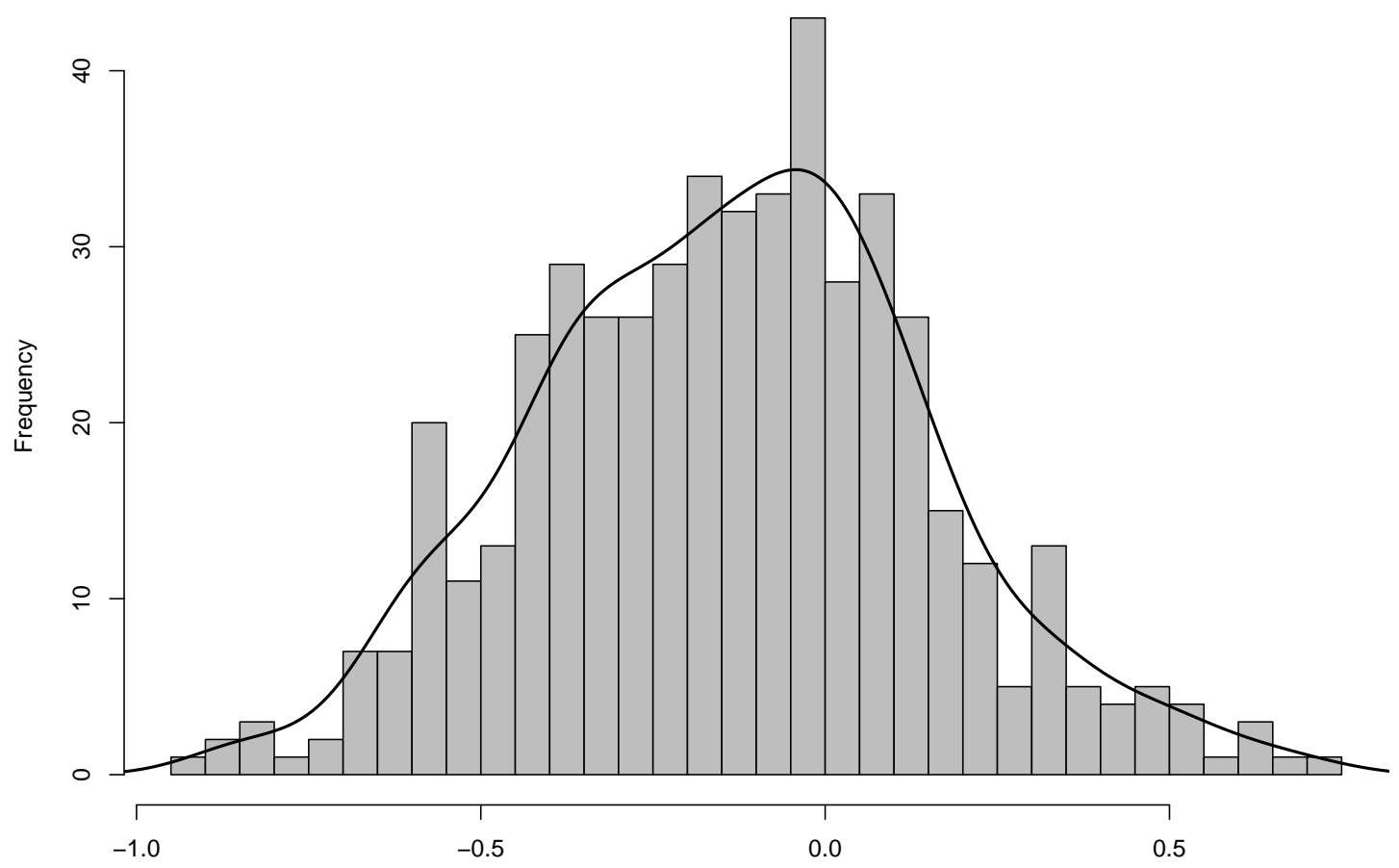

